\title{
The structure of the cometary globule CG 12: a high-latitude star-forming region $\star, \star \star$
}

\author{
L. K. Haikala ${ }^{1,2}$ and M. Olberg ${ }^{3}$ \\ 1 Observatory, PO Box 14, University of Helsinki, Finland \\ e-mail: haikala@astro.helsinki.fi \\ 2 Swedish-ESO Submillimetre Telescope, European Southern Observatory, Casilla 19001, Santiago, Chile \\ 3 Onsala Space Observatory, 43900 Onsala, Sweden \\ e-mail: michael. olberg@chalmers.se
}

Received 23 March 2006 / Accepted 22 September 2006

ABSTRACT

\begin{abstract}
We have investigated the structure of the high galactic-latitude cometary globule 12 (CG 12) by means of radio molecular-line observations. Detailed, high signal-to-noise ratio maps in $\mathrm{C}^{18} \mathrm{O}(1-0), \mathrm{C}^{18} \mathrm{O}(2-1)$ and molecules tracing high-density gas, CS (3-2), $\mathrm{DCO}^{+}(2-1)$, and $\mathrm{H}^{13} \mathrm{CO}^{+}(1-0)$, are presented. The $\mathrm{C}^{18} \mathrm{O}$ line emission is distributed in a $10^{\prime}$ long North-South elongated lane with two strong maxima, CG 12-N(orth) and CG 12-S(outh). In CG 12-S the high-density tracers delineate a compact core, $\mathrm{DCO}^{+}$core, which is offset by $15^{\prime \prime}$ from the $\mathrm{C}^{18} \mathrm{O}$ maximum. The observed strong $\mathrm{C}^{18} \mathrm{O}$ emission traces either the surface of the $\mathrm{DCO}^{+}$core or a separate, adjacent cloud component. The driving source of the collimated molecular outflow detected in 1993 is located in the $\mathrm{DCO}^{+}$ core. The $\mathrm{C}^{18} \mathrm{O}$ lines in $\mathrm{CG} 12-\mathrm{S}$ have low-intensity wings possibly caused by the outflow. The emission in high-density tracers is weak in $\mathrm{CG} 12-\mathrm{N}$ and especially the $\mathrm{H}^{13} \mathrm{CO}^{+}$, $\mathrm{DCO}^{+}$, and $\mathrm{N}_{2} \mathrm{H}^{+}$lines are $+0.5 \mathrm{~km} \mathrm{~s}^{-1}$ offset in velocity with respect to the $\mathrm{C}^{18} \mathrm{O}$ lines. Evidence is presented that the molecular gas is highly depleted. The observed strong $\mathrm{C}^{18} \mathrm{O}$ emission towards $\mathrm{CG} 12-\mathrm{N}$ originates in the envelope of this depleted cloud component or in a separate entity seen in the same line of sight. The $\mathrm{C}^{18} \mathrm{O}$ lines in $\mathrm{CG} 12$ were analysed using positive matrix factorization, PMF. The shape and the spatial distribution of the individual PMF factors fitted separately to the $\mathrm{C}^{18} \mathrm{O}(1-0)$ and $(2-1)$ transitions were consistent with each other. The results indicate a complex velocity and line excitation structure in the cloud. Besides separate cloud velocity components the $\mathrm{C}^{18} \mathrm{O}$ line shapes and intensities are influenced by excitation temperature variations caused by e.g., the molecular outflow or by molecular depletion. Assuming a distance of $630 \mathrm{pc}$ the size of the CG 12 compact head, $1.1 \mathrm{pc}$ by $1.8 \mathrm{pc}$, and the $\mathrm{C}^{18} \mathrm{O}$ mass larger than $100 M_{\odot}$ are comparable to those of other nearby low/intermediate mass star formation regions.
\end{abstract}

Key words. clouds - ISM molecules - ISM: structure - radio lines - ISM: individual objects: CG 12 ISM: individual objects: NGC 5367

\section{Introduction}

Herschel (1847) noted that a 10th mag. star, now known as h4636 or $\mathrm{CoD}-39^{\circ} 8581$, is a binary with a separation of 3.'7. In the optical, h4636 illuminates the bright reflection nebula NGC 5367. Hawarden \& Brand (1976) showed that it lies in the head of an impressive cometary globule $12, \mathrm{CG} 12$, with a tail stretching about one degree to the SE. With a galactic latitude of $21^{\circ}$ and at the distance of $630 \mathrm{pc}$ estimated by Williams et al. (1977), CG 12 lies more than 200 pc above the plane. It has an associated low/intermediate mass stellar cluster that has at least 9 members (Williams et al. 1977).

The cloud's cometary structure could be due to the passage of a supernova blast wave. Curiously, the cometary tail stretches towards the Galactic plane, which would place the putative supernova even farther away from the Galactic plane than the globule. According to Maheswar et al. (1996), the head of CG 12 is pointing towards the centre of an HI shell. Such a shell is, however, not readily evident in the whole-sky HI survey (Kalberla et al. 2005), which merges the northern

\footnotetext{
* Based on observations collected at the European Southern
} Observatory, La Silla, Chile.

$\star \star$ Figures 11 and 12 and Appendix A are only available in electronic form via http://www . aanda.org
Leiden/Dwingeloo Survey (Hartman \& Burton 1997) and the southern Instituto Argentino de Radioastronomia Survey (Arnal et al. 2000). The CG 12 cloud cometary shape is also seen in the IRAS surface emission (Odenwald 1988).

White (1993) mapped the region around and south of h4636 in ${ }^{12} \mathrm{CO}(2-1)$ and $\mathrm{C}^{18} \mathrm{O}(2-1)$ lines with a spatial resolution of $22^{\prime \prime}$. He found a small $\mathrm{C}^{18} \mathrm{O}$ core near the binary and a molecular outflow with a centre close to the binary system. Further large-scale ${ }^{12} \mathrm{CO},{ }^{13} \mathrm{CO}$, and $\mathrm{C}^{18} \mathrm{O}$ observations with 2!7 resolution are presented in Yonekura et al. (1999). CG 12 contains two compact $1.2 \mathrm{~mm}$ continuum sources, one in the direction of the $\mathrm{C}^{18} \mathrm{O}$ core detected by White (1993) (Reipurth et al. 1996) and another one two arcminutes north of it (Haikala 2007, in preparation). The centres of the continuum sources were observed in $\mathrm{C}^{18} \mathrm{O}(3-2)$ by Haikala et al. (2006).

Near-infrared $(J, H$, and $K)$ images and photometry of stars in CG 12 are available in the 2MASS survey and in Santos et al. (1998). A deeper $J, H$, and $K$ s imaging study is presented in Haikala (2007, in preparation). Far-infrared emission in CG 12 is dominated by a strong point source, IRAS 13547-3944, near the binary h4636. 
CG 12/NGC 5367 is an intriguing object. It has the appearance of a cometary globule such as usually found on the outskirts of HII regions. The linear size of cometary globules, like those in the Gum nebula, are however much smaller (e.g., Reipurth 1983). The linear extent of CG 12, $10 \mathrm{pc}$, is four times larger than, e.g., the archetype object CG 1 . A low/intermediate mass stellar cluster is associated with CG 12. Perhaps the most curious feature of CG 12 is its location over 200 pc above the Galactic plane with no sign of other nearby dark clouds or star formation. CG 12 has not attracted much interest since the identification of the stellar cluster (Williams et al. 1977) and the Hawarden \& Brand (1976) cometary globule paper. Subsequent papers have either concentrated on the Herbig AeBe binary, h4636, or the cloud has been included in various surveys. The ${ }^{12} \mathrm{CO}(2-1)$ and $\mathrm{C}^{18} \mathrm{O}(2-1)$ observations by White (1993), though detailed, cover only the very centre of the cloud. What has been missing is a detailed, but at the same time extended, study of the dense CG 12 molecular cloud in molecular transitions that are sensitive to the large-scale structure (cloud envelope) and to the detailed structure of the high-density material (cores).

In this paper we report the mapping of the head of CG 12 in the $\mathrm{C}^{18} \mathrm{O}(1-0)$ and $(2-1)$ and in ${ }^{13} \mathrm{CO}(1-0)$ lines. The $\mathrm{C}^{18} \mathrm{O}$ emission maxima were further mapped in $\mathrm{DCO}^{+}(2-1), \mathrm{H}^{13} \mathrm{CO}^{+}(1-0)$, and $\mathrm{CS}(2-1)$ and (3-2). More pointed observations with a long integration time in $\mathrm{CO}(1-0)$ and (2-1) (and isotopologues), CS (2-1) and (3-2), $\mathrm{C}^{34} \mathrm{~S}(2-1)$, $\mathrm{H}^{13} \mathrm{CO}^{+}(1-0), \mathrm{DCO}^{+}(2-1)$, and $\mathrm{N}_{2} \mathrm{H}^{+}(1-0)$ were made towards selected positions in the cloud.

Observations, data reduction, and calibration procedures are described in Sect. 2 and the observational results in Sect. 3. The new results are compared with the optical and NIR images in Sect. 4. In Sect. 5 and Appendix A, PMF is used to analyse the $\mathrm{C}^{18} \mathrm{O}$ small-scale structure in the globule. In the discussion part in Sect. 6, the $\mathrm{C}^{18} \mathrm{O}$ column densities and the cloud mass are derived and the observational and calculated results are summarised. The conclusions are drawn in Sect. 7.

\section{Observations}

The observations were made during various observing runs with the Swedish-ESO-Submillimetre-Telescope, SEST, at the La Silla observatory, Chile. The SEST $3 \mathrm{~mm}$ dual polarization, single sideband (SSB), Schotky receiver was used for the ${ }^{13} \mathrm{CO}(1-0)$ and $\mathrm{CS}(2-1)$ mapping observations. The rest of the observations were conducted with the SEST 3 and $2 \mathrm{~mm}$ (SESIS) and 3 and $1 \mathrm{~mm}$ (IRAM) dual SiS SSB receivers. The SEST high-resolution, 2000-channel acousto-optical spectrometer (bandwidth $86 \mathrm{MHz}$, channel width $43 \mathrm{kHz}$ ) was split into two halves to measure two receivers simultaneously. At the observed wavelengths, $3 \mathrm{~mm}, 2 \mathrm{~mm}$, and $1 \mathrm{~mm}$, the $43 \mathrm{kHz}$ channel width corresponds to $\sim 0.12 \mathrm{~km} \mathrm{~s}^{-1}, \sim 0.08 \mathrm{~km} \mathrm{~s}^{-1}$, and $\sim 0.06 \mathrm{~km} \mathrm{~s}^{-1}$, respectively.

Frequency-switching observing mode was used and a second-order baseline was subtracted from the spectra after folding. Calibration was achieved by the chopper wheel method. All the line temperatures in this paper, if not especially noted, are in the units of $T_{\mathrm{A}}^{*}$, i.e. corrected to outside of the atmosphere but not for beam coupling. Typical values for the effective SSB system temperatures outside the atmosphere ranged from $200 \mathrm{~K}$ to $350 \mathrm{~K}$. Pointing was checked regularly in continuum mode towards the nearby Centaurus A galaxy and the pointing accuracy is estimated to be better than $5^{\prime \prime}$.

The observed molecular transitions, their frequencies, SEST half power beam width, $H P B W$, and the telescope main beam
Table 1. Observed lines and telescope parameters.

\begin{tabular}{lrcc}
\hline \hline Line & $v[\mathrm{GHz}]$ & $H P B W\left[{ }^{\prime \prime}\right]$ & $\eta_{\mathrm{mb}}$ \\
\hline $\mathrm{H}^{13} \mathrm{CO}^{+}(1-0)$ & 86.754 & 57 & 0.75 \\
$\mathrm{~N}_{2} \mathrm{H}^{+}(1-0)$ & 93.176 & 54 & \\
$\mathrm{C}^{34} \mathrm{~S}(2-1)$ & 96.412 & 54 & \\
$\mathrm{CS}(2-1)$ & 97.271 & 54 & \\
$\mathrm{C}^{18} \mathrm{O}(1-0)$ & 109.782 & 47 & 0.70 \\
$\mathrm{DCO}^{+}(2-1)$ & 144.077 & 34 & \\
$\mathrm{CS}(3-2)$ & 145.904 & 34 & 0.66 \\
$\mathrm{C}^{18} \mathrm{O}(2-1)$ & 219.560 & 24 & 0.50 \\
\hline
\end{tabular}

efficiency, $\eta_{\mathrm{mb}}$, at these frequencies are given in Table 1 . For the $\mathrm{CO}$ observations only the $\mathrm{C}^{18} \mathrm{O}$ is listed. At a distance of $630 \mathrm{pc}$ the SEST HPBW at $219 \mathrm{GHz}$ corresponds to $0.07 \mathrm{pc}$.

The cloud was mapped simultaneously in $\mathrm{C}^{18} \mathrm{O}(1-0)$ and $\mathrm{C}^{18} \mathrm{O}(2-1)$ transitions with a spacing of $20^{\prime \prime}$ (514 positions). The map central position was $13^{\mathrm{h}} 57^{\mathrm{m}} 43^{\mathrm{s}} .1,-39^{\circ} 58^{\prime} 43^{\prime \prime} \cdot 3$ (J2000), which is $-5^{\prime \prime}$ and $\sim-10^{\prime \prime}$ in right ascension from the positions of the IRAS 13547-3944 point source and the binary $\mathrm{h} 3626$, respectively. The average rms of the spectra were $0.07 \mathrm{~K}$ and $0.09 \mathrm{~K}$ for $\mathrm{C}^{18} \mathrm{O}(1-0)$ and (2-1), respectively. An approximately $8^{\prime}$ by $20^{\prime}$ area was mapped in ${ }^{13} \mathrm{CO}$ using $40^{\prime \prime}$ spacing (324 positions). The $\mathrm{C}^{18} \mathrm{O}$ maxima were mapped in $\mathrm{CS}(2-1),(3-2), \mathrm{DCO}^{+}(2-1)$, and $\mathrm{H}^{13} \mathrm{CO}^{+}(1-0)$. Further long integration time pointed observations in $\mathrm{CO}, \mathrm{CS}, \mathrm{H}^{13} \mathrm{CO}^{+}, \mathrm{DCO}^{+}, \mathrm{C}^{34} \mathrm{~S}$, and $\mathrm{N}_{2} \mathrm{H}^{+}$were made.

\section{Results}

The mapping of CG 12 in $\mathrm{C}^{18} \mathrm{O}$ and in molecules tracing highdensity material provides a large-scale view of the cloud. High signal-to-noise spectra in selected molecular transitions were obtained by pointed observations with a long integration time. These spectra probe the cloud at different depths and densities. Combining the intensity and velocity information in the pointed spectra provides a clue to the cloud fine-scale structure.

\section{1. $\mathrm{CO}$}

The observed distributions of $\mathrm{C}^{18} \mathrm{O}(1-0)$ and $\mathrm{C}^{18} \mathrm{O}(2-1)$ line emission towards CG12 are presented in Fig. 1 (the $\int T_{\mathrm{A}}^{*} \mathrm{~d} v$ in the velocity range $-8 \mathrm{~km} \mathrm{~s}^{-1}$ to $-4 \mathrm{~km} \mathrm{~s}^{-1}$ ) and Figs. 11 and $12\left(\mathrm{C}^{18} \mathrm{O}\right.$ channel maps). In the figures the grey/colour scales and the contour levels are the same for the two $\mathrm{C}^{18} \mathrm{O}$ transitions. The offsets from the map centre position in arc minutes are shown on the axes of the right panel in Fig. 1.

The bulk of the molecular material traced by $\mathrm{C}^{18} \mathrm{O}$ emission is distributed in a narrow North-South oriented lane with two prominent maxima. A less intense maximum is observed to the SW. Henceforth the three intensity maxima will be referred to as CG 12-N, CG 12-S, and CG 12-SW, where CG 12-S corresponds to the $\mathrm{C}^{18} \mathrm{O}(2-1)$ maximum reported in White (1993).

The morphology of the cloud is similar in the two $\mathrm{C}^{18} \mathrm{O}$ transitions. However, there is a notable difference between the $\mathrm{C}^{18} \mathrm{O}$ maxima. The observed $\mathrm{C}^{18} \mathrm{O}(1-0)$ emission is stronger than the $\mathrm{C}^{18} \mathrm{O}(2-1)$ emission in $\mathrm{CG} 12-\mathrm{N}$ and $\mathrm{CG} 12-\mathrm{SW}$, whereas in CG 12-S the opposite is the case. In CG 12-N the $\mathrm{C}^{18} \mathrm{O}(1-0)$ line remains stronger than the $(2-1)$ line even when expressed on the main beam brightness-temperature scale. 


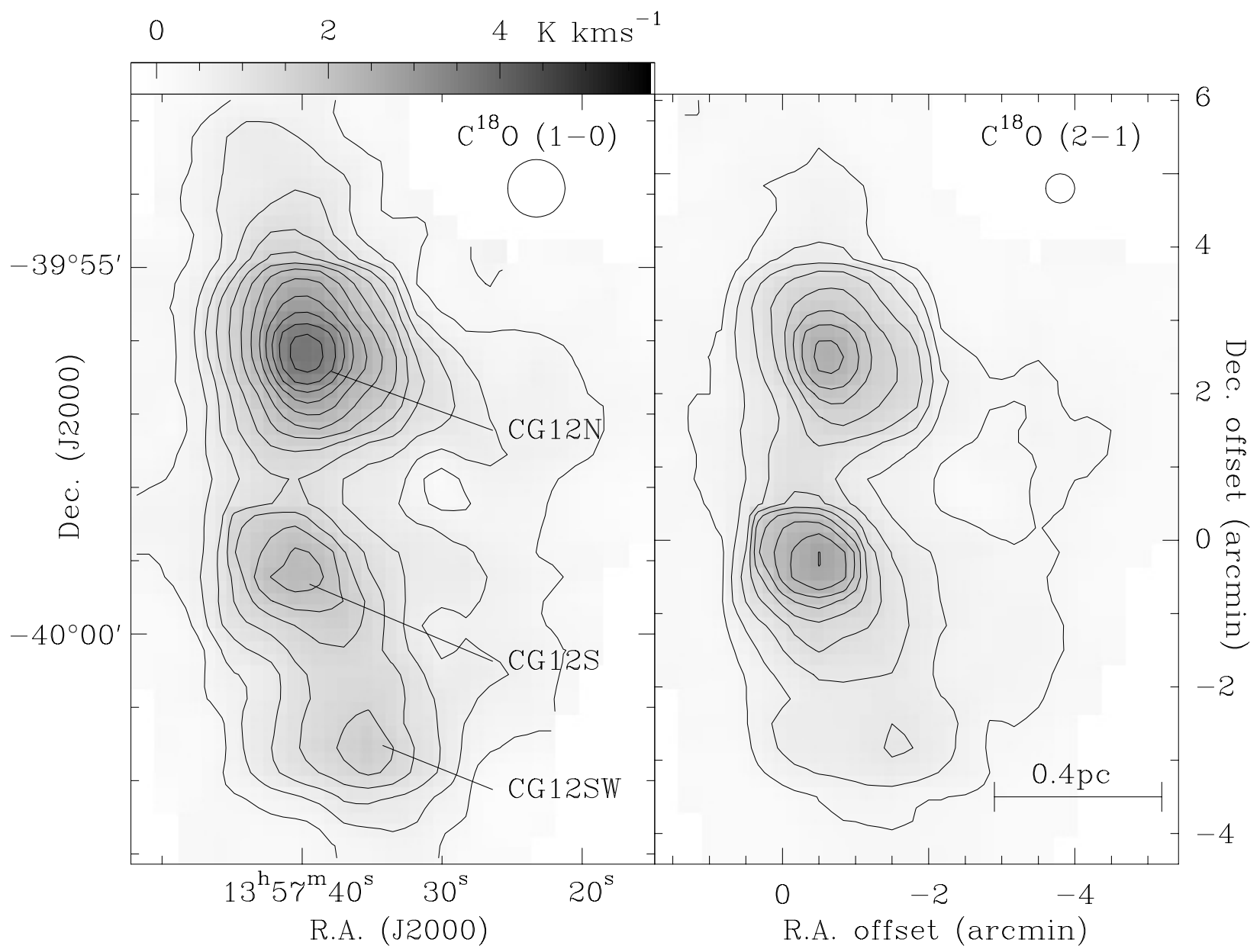

Fig. 1. Maps of integrated emission of $\mathrm{C}^{18} \mathrm{O}(1-0)$ and $\mathrm{C}^{18} \mathrm{O}(2-1) \int T_{\mathrm{A}}^{*} \mathrm{~d} v$ from $-8 \mathrm{~km} \mathrm{~s}^{-1}$ to $-4 \mathrm{~km} \mathrm{~s}^{-1}$ in CG12. The lowest contour and the contour increment are $0.3 \mathrm{~K} \mathrm{~km} \mathrm{~s}^{-1}$. The SEST half-power beam sizes are shown in the upper corners of the panels. Offsets from the map's central position, $13^{\mathrm{h}} 57^{\mathrm{m}} 43^{\mathrm{s}} \cdot 1,-39^{\circ} 58^{\prime} 43^{\prime \prime} \cdot 3(\mathrm{~J} 2000)$, are shown on the axes of the right panel. The scale tick in the lower right corner assumes a distance of $630 \mathrm{pc}$ to the cloud.

More details can be seen in Figs. 11 and 12, which reveal that the structure of the cloud is not as simple as Fig. 1 suggests. The most noticeable features are the following: CG $12-\mathrm{N}$ is elongated in the North South direction at velocities $\leq-6.0 \mathrm{~km} \mathrm{~s}^{-1}$ and in the East West direction at velocities $\geq-5.4 \mathrm{~km} \mathrm{~s}^{-1}$. The position of the maximum $\mathrm{C}^{18} \mathrm{O}(2-1)$ emission in $\mathrm{CG} 12-\mathrm{S}$ moves from below the map centre position (marked with a cross in the figure) at $-7.0 \mathrm{~km} \mathrm{~s}^{-1}$ to a position $40^{\prime \prime}$ west of this position at velocity $-5.9 \mathrm{~km} \mathrm{~s}^{-1}$. An arc-like feature connects CG $12-\mathrm{S}$ and CG 12-SW at velocities from $-6.6 \mathrm{~km} \mathrm{~s}^{-1}$ to $-6.2 \mathrm{~km} \mathrm{~s}^{-1}$. The arc is less pronounced in the $\mathrm{C}^{18} \mathrm{O}(2-1)$ transition.

The observed distribution of the ${ }^{13} \mathrm{CO}(1-0)$ line emission towards CG12 is presented in Fig. 2. The extent of the $\mathrm{C}^{18} \mathrm{O}$ mapping and the outline of the $\mathrm{C}^{18} \mathrm{O}(2-1)$ emission is indicated in the overlay. The notable difference between the observed $\mathrm{C}^{18} \mathrm{O}$ and ${ }^{13} \mathrm{CO}$ emission is that there is only one ${ }^{13} \mathrm{CO}$ maximum, which is offset to NE from CG 12-S. In particular, there is no indication of CG $12-\mathrm{N}$ on the ${ }^{13} \mathrm{CO}$ map.

The ${ }^{12} \mathrm{CO},{ }^{13} \mathrm{CO}$, and $\mathrm{C}^{18} \mathrm{O}(1-0)$ and $(2-1)$ (pointed, long integration time) spectra in five selected positions in the cloud are shown in Fig. 3. The ${ }^{12} \mathrm{CO}$ spectra observed at all positions in the figure are strongly self-absorbed. Therefore the ${ }^{12} \mathrm{CO}$ line peak intensity, line half width, and the line integral are not physically meaningful. Line wing emission due to a molecular outflow (White 1993) is seen in all ${ }^{12} \mathrm{CO}$ spectra, also in the direction of CG 12-N, which was not covered by the White (1993) observations.

\section{2. high-density tracers, mapping}

In the optically thin case the critical density of the $\mathrm{C}^{18} \mathrm{O}$ (1-0) transition is $\sim 650 \mathrm{~cm}^{-3}$ and approximately ten times this value for the (2-1) transition (Rohlfs \& Wilson 1999). These $\mathrm{C}^{18} \mathrm{O}$ lines are therefore already excited at low densities, and their emission traces column density rather than number density. Therefore the $\mathrm{C}^{18} \mathrm{O}$ intensity maxima were also mapped in the high-density tracers (critical densities larger than $\left.10^{5} \mathrm{~cm}^{-3}\right) \mathrm{CS}(2-1), \mathrm{H}^{13} \mathrm{CO}^{+}(1-0)$ and $\mathrm{DCO}^{+}(2-1)$ using $20^{\prime \prime}$ spacing. A 4 by 4 point map with the same spacing was obtained for CG 12-S in the CS (3-2) line.

Contour maps of the CS $(2-1), \mathrm{CS}(3-2), \mathrm{H}^{13} \mathrm{CO}^{+}$, and $\mathrm{DCO}^{+}$line integral in $\mathrm{CG} 12$ superposed on the $\mathrm{C}^{18} \mathrm{O}(2-1)$ emission (grey scale) are shown in Fig. 4. CG 12-N was not mapped in CS (3-2). The CS (2-1) emission peaks at the position of the $\mathrm{C}^{18} \mathrm{O}(2-1)$ the maximum in CG 12-S. In other molecules the maximum is shifted to SE from the $\mathrm{C}^{18} \mathrm{O}$ maximum. As $\mathrm{DCO}^{+}$traces high-density gas, the CG 12-S $\mathrm{DCO}^{+}$maximum will be referred to as the $\mathrm{DCO}^{+}$core. 


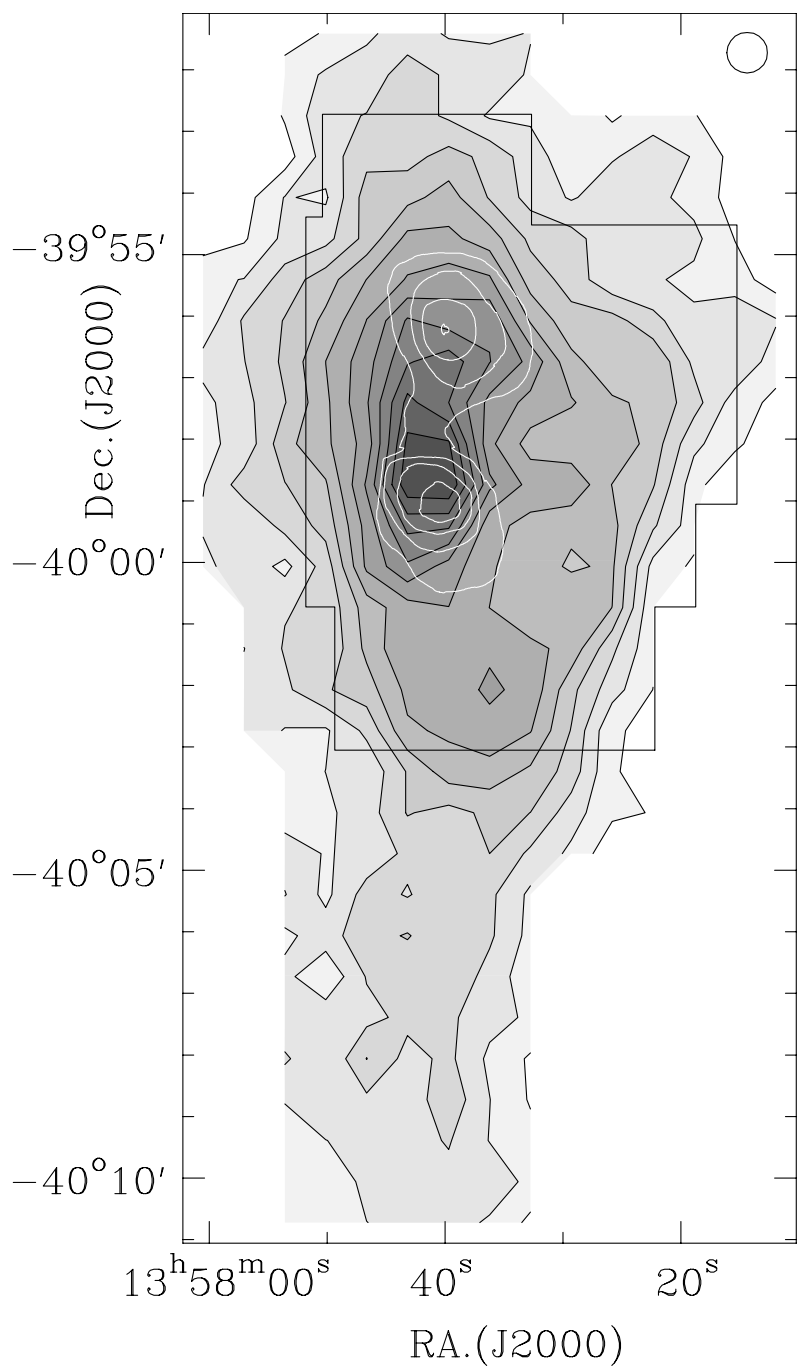

Fig. 2. Map of integrated emission of ${ }^{13} \mathrm{C} 0 \quad(1-0)$ : $\int T_{\mathrm{A}}^{*} \mathrm{~d} v$ from $-8 \mathrm{~km} \mathrm{~s}^{-1}$ to $-4 \mathrm{~km} \mathrm{~s}^{-1}$. The lowest contour and the contour increment are $1.2 \mathrm{~K} \mathrm{~km} \mathrm{~s}^{-1}$. The SEST half-power beam size at the line frequency is shown in the upper corner. The extent of the $\mathrm{C}^{18} \mathrm{O}$ mapping and the outline of the $\mathrm{C}^{18} \mathrm{O}(2-1)$ emission is indicated in the overlay.

\section{3. $\mathrm{C}^{18} \mathrm{O}$ and high-density tracers: pointed observations}

Pointed, long-integration-time CS (2-1), (3-2), $\mathrm{C}^{34} \mathrm{~S}(2-1)$, $\mathrm{H}^{13} \mathrm{CO}^{+}(1-0), \mathrm{DCO}^{+}(2-1)$, and $\mathrm{N}_{2} \mathrm{H}^{+}(1-0)$ spectra in the same positions as in Fig. 3 are shown in Fig. 5. The integration time of the CS $(3-2)$ line at position $\left(-40^{\prime \prime},-20^{\prime \prime}\right)$ is only $2.5 \mathrm{~min}$ and is therefore noisier than the two other CS (3-2) lines. The $\mathrm{N}_{2} \mathrm{H}^{+}$(1-0) line consists of seven hyperfine components, and only the unblended $\mathrm{N}_{2} \mathrm{H}^{+}(1-0)\left(\mathrm{F}_{1}\right.$, $F=0,1 \rightarrow 1,2$ ) component is shown in Fig. 5 .

The $C^{34} \mathrm{~S}$ line was observed in three positions. These spectra together with the CS (2-1) and (3-2) spectra observed at the same positions are shown in Fig. 6 . The $\mathrm{N}_{2} \mathrm{H}^{+}$spectra showing all the hyperfine components in the three observed positions are shown in Fig. 7. Also the hyperfine component fits (assuming optically thin emission and one velocity component) and their residuals are shown.

\subsubsection{CG 12-S}

Near the centre of the $\mathrm{DCO}^{+}$core (position $-20^{\prime \prime},-20^{\prime \prime}$ ), the $\mathrm{H}^{13} \mathrm{CO}^{+}, \mathrm{DCO}^{+}$and $\mathrm{N}_{2} \mathrm{H}^{+}$lines are nearly symmetric and centred at velocity $-6.5 \mathrm{~km} \mathrm{~s}^{-1}$. The $\mathrm{C}^{18} \mathrm{O}$ lines are skewed and the maximum intensity is redshifted from the $\mathrm{DCO}^{+}(2-1)$ peak velocity. Going to the West (position $-40^{\prime \prime},-20^{\prime \prime}$ ) the redshifted side of the $\mathrm{C}^{18} \mathrm{O}$ lines becomes more intense. Low-intensity wing-like emission is observed in the $\mathrm{C}^{18} \mathrm{O}$ and $\mathrm{CS}(2-1)$ lines in the direction of the $\mathrm{DCO}^{+}$core and position $\left(0^{\prime \prime}, 0^{\prime \prime}\right)$.

The $\mathrm{N}_{2} \mathrm{H}^{+}$line in the position $\left(-20^{\prime \prime},-20^{\prime \prime}\right)$, can be fit with a single velocity component centred at $-6.56 \mathrm{~km} \mathrm{~s}^{-1}$ (Fig. 7 , lower panel). Due to the $0.73 \mathrm{~km} \mathrm{~s}^{-1}$ line half width, the hyperfine components are blended and the hyperfine structure is only marginally resolved. The signal-to-noise ratio of the spectrum is not sufficient to meaningfully fit the line total optical depth, $\tau_{\text {tot }}$. The estimated $\tau_{\text {tot }}$ upper limit in this position is 5 .

\subsection{2. $\mathrm{CG} 12-\mathrm{N}$}

In CG $12-\mathrm{N}$ (position $-40^{\prime \prime}, 160^{\prime \prime}$ ), the $\mathrm{C}^{18} \mathrm{O}$ lines are nearly symmetric but not Gaussian. The emission from the high-density tracers is weak when compared to what is observed in CG 12-S.

The $\mathrm{C}^{34} \mathrm{~S}$ line was observed in two positions in CG 12-N (Fig. 6). The CS(2-1) and (3-2) line profiles in these positions are not Gaussian and may be composed of two or three components. The peak intensity of the $C^{34} S(2-1)$ line is redshifted with respect to the peak of the CS (3-2) line, which itself is redshifted with respect to the CS (2-1) line, which peaks approximately at the same velocity as the $\mathrm{C}^{18} \mathrm{O}$ lines.

The observed ionic lines $\left(\mathrm{DCO}^{+}(2-1), \mathrm{H}^{13} \mathrm{CO}^{+}(1-0)\right.$, and $\mathrm{N}_{2} \mathrm{H}^{+}(1-0)$ ) are offset $+0.5 \mathrm{~km} \mathrm{~s}^{-1}$ in velocity with respect to the $\mathrm{C}^{18} \mathrm{O}$ lines and peak at a velocity where especially the $\mathrm{C}^{18} \mathrm{O}(2-1)$ line intensity is low.

The $\mathrm{N}_{2} \mathrm{H}^{+}(1-0)$ line was observed in the same two positions as $\mathrm{C}^{34} \mathrm{~S}$. In contrast to the CS lines, the observed $\mathrm{N}_{2} \mathrm{H}^{+}$lines are identical within the noise (Fig. 7, two upper panels). The SEST beam is the same at $\mathrm{CS}(2-1)$ and $\mathrm{N}_{2} \mathrm{H}^{+}(1-0)$ frequencies. A hyperfine component fit to the $\mathrm{CG} 12-\mathrm{N} \mathrm{N}_{2} \mathrm{H}^{+}$lines gives a $0.65 \mathrm{~km} \mathrm{~s}^{-1}$ broad line at $-5.41 \mathrm{~km} \mathrm{~s}^{-1}$. The estimated $\tau_{\text {tot }}$ upper limit in position $\left(-40^{\prime \prime},-160^{\prime \prime}\right)$ is 2 .

To rule out the observed intensity/velocity structure described above being due to calibration, pointing, or frequency setting problems, the observations were carefully checked by observing the $\mathrm{C}^{18} \mathrm{O}$ and the $\mathrm{DCO}^{+}, \mathrm{H}^{13} \mathrm{CO}^{+}$and $\mathrm{CS}$ lines one after the other and making pointing checks before and after observations. Also, e.g., the line pair $\mathrm{DCO}^{+}(2-1)$ and $\mathrm{C}^{18} \mathrm{O}(1-0)$ could be observed simultaneously with a dual receiver, thus excluding relative pointing errors.

\section{Comparison with observations at other wavelengths}

The $\mathrm{C}^{18} \mathrm{O}(2-1)$ contour map superposed on the blue SERC-J DSS image is shown in Fig. 8. The bright optical reflection nebula NGC 5367 lies in front of CG 12-S, whereas CG $12-\mathrm{N}$ is in the direction of an optically heavily-obscured region that is clearly seen in the inset. A $1.2 \mathrm{~mm}$ source (Haikala 2007, in preparation) coincides with the position of the $\mathrm{CG} 12-\mathrm{N} \mathrm{C}^{18} \mathrm{O}$ maximum.

A $K$ s band image (Haikala 2007, in preparation) of CG 12 is shown in Fig. 9. Superposed on the image are the contours of the ${ }^{12} \mathrm{CO}(2-1)$ molecular-outflow line-wing emission (White 1993). In the insets, the $\mathrm{C}^{18} \mathrm{O}(2-1)$ and $\mathrm{DCO}^{+}$ 


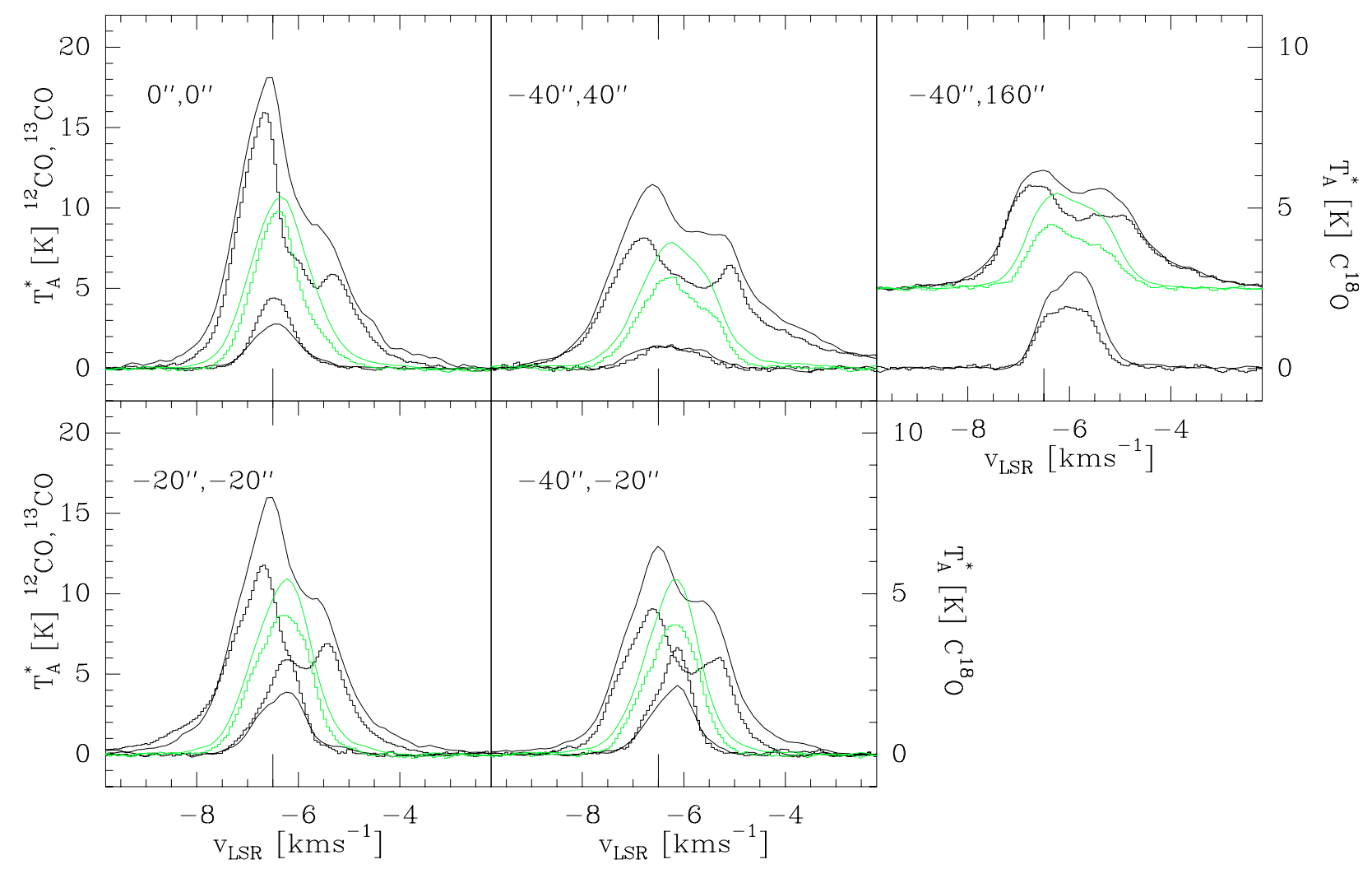

Fig. 3. ${ }^{12} \mathrm{CO},{ }^{13} \mathrm{CO}$, and $\mathrm{C}^{18} \mathrm{O}$ spectra observed towards five selected positions in $\mathrm{CG} 12$. The offset from the map centre position is shown in arc seconds in the upper left corners of each panel. A line has been used for the (1-0) and a histogram for the (2-1) transitions. The antenna temperature scale at left is for ${ }^{12} \mathrm{CO}$ and ${ }^{13} \mathrm{CO}$ spectra and the one on the right for $\mathrm{C}^{18} \mathrm{O}$. The velocity tick indicates a velocity of $-6.5 \mathrm{~km} \mathrm{~s}{ }^{-1}$. The ${ }^{12} \mathrm{CO}$ and ${ }^{13} \mathrm{CO}$ spectra in position $\left(-40^{\prime \prime}, 160^{\prime \prime}\right)$ are offset from the zero level for clarity.

contour maps are superposed, together with the positional uncertainty ellipses of IRAS point sources IRAS 13546-3941 and IRAS 13547-3944. IRAS 13547-3944 does not coincide with the binary h4636. The base of the binary star emission is saturated due to the intensity scale which was chosen to emphasize the low intensity surface emission.

A cone-like nebulosity with a bright head is seen projected on the $\mathrm{DCO}^{+}$core in Fig. 9. The apex of the cone is located just off the tip of the red shifted and below the end of the blue shifted, collimated CO outflow lobes of White (1993). A compact $1.2 \mathrm{~mm}$ source (Haikala 2007, in preparation) coincides with the $\mathrm{DCO}^{+}$core. The core does not have an associated point source, but this could be due to the low spatial resolution of the IRAS satellite. A faint source would be masked by the strong nearby source IRAS 13547-3944. The NIR cone could be associated with the driving source of the outflow. The centre of the molecular outflow is offset from the position of IRAS $13547-3944$ by $\sim 20^{\prime \prime}$. It is unlikely that the point source is associated with the large outflow, but it could be the driving force for the strong redshifted outflow lobe located $\sim 1^{\prime} \mathrm{NW}$ of the nominal position of the point source.

Small areas of the size of the SEST HPBW at the $\mathrm{C}^{18} \mathrm{O}(1-0)$ frequency in the centres of CG $12-\mathrm{N}$ and CG $12-\mathrm{S}$ have been mapped in the $\mathrm{C}^{18} \mathrm{O}(3-2)$ (Haikala et al. 2006). The $H P B W$ of the $\mathrm{C}^{18} \mathrm{O}(3-2)$ observations is $19^{\prime \prime}$, which is similar to the SEST $H P B W$ of $24^{\prime \prime}$ at the $\mathrm{C}^{18} \mathrm{O}(2-1)$ frequency. In CG $12-\mathrm{S}$, the $\mathrm{C}^{18} \mathrm{O}(3-2)$ emission has a strong maximum in the same position as the maxima in the lower $\mathrm{C}^{18} \mathrm{O}$ transitions. The line profile in position $\left(-20^{\prime \prime},-20^{\prime \prime}\right)$ agrees with the $\mathrm{C}^{18} \mathrm{O}(2-1)$ line (Fig. 5). The $\mathrm{C}^{18} \mathrm{O}(3-2) T_{\mathrm{MB}}$ peak line temperature in this position is, however, $10 \mathrm{~K}$, which is nearly twice the
$\mathrm{C}^{18} \mathrm{O}(2-1) T_{\mathrm{MB}}$ of $5.7 \mathrm{~K}$. In CG 12-N (position $\left(-40^{\prime \prime}, 160^{\prime \prime}\right)$, the $\mathrm{C}^{18} \mathrm{O}(3-2)$ line profile is similar to that of $\mathrm{C}^{18} \mathrm{O}(1-0)$, but the $T_{\mathrm{MB}}$ peak line temperature is $3 \mathrm{~K}$, which is lower than the corresponding values observed in $\mathrm{C}^{18} \mathrm{O}(1-0)$ and $(2-1)$, which are $4.3 \mathrm{~K}$ and $3.8 \mathrm{~K}$, respectively.

\section{5. $\mathrm{C}^{18} \mathrm{O}$ fine-scale structure}

The half widths of the observed $\mathrm{C}^{18} \mathrm{O}$ lines in $\mathrm{CG} 12$ cores range from $1.0 \mathrm{~km} \mathrm{~s}^{-1}$ (CG 12-S) to $1.3 \mathrm{~km} \mathrm{~s}^{-1}$ (CG 12-N). The $\mathrm{C}^{18} \mathrm{O}$ channel-maps (Figs. 11 and 12) and observations of other molecules indicate that the lines consist of more than one velocity component. This division of the cloud according to its appearance in the $\mathrm{C}^{18} \mathrm{O}$ line integral maps (Fig. 1) into only three components CG 12-N, CG 12-S, and CG 12-SW is therefore too coarse. The fine structure within the individual maxima is not seen because the lines are heavily blended in velocity.

\subsection{Positive matrix factorization}

Positive matrix factorization (PMF) has been used by Juvela et al. (1996) and Russeil et al. (2003) in the analysis of molecular line spectral maps. It assumes that the ensemble of input spectra are composed of $n$ individual line components (factors). Unlike principal component analysis PMF assumes that the individual components are positive. This makes the interpretation of the results more straightforward than in principal component analysis where the results may contain negative components. No other assumptions are made for the shape of the factors. Each input spectrum can be reconstructed from the $n$ PMF output factors by multiplying each factor by the weight assigned to it by PMF 


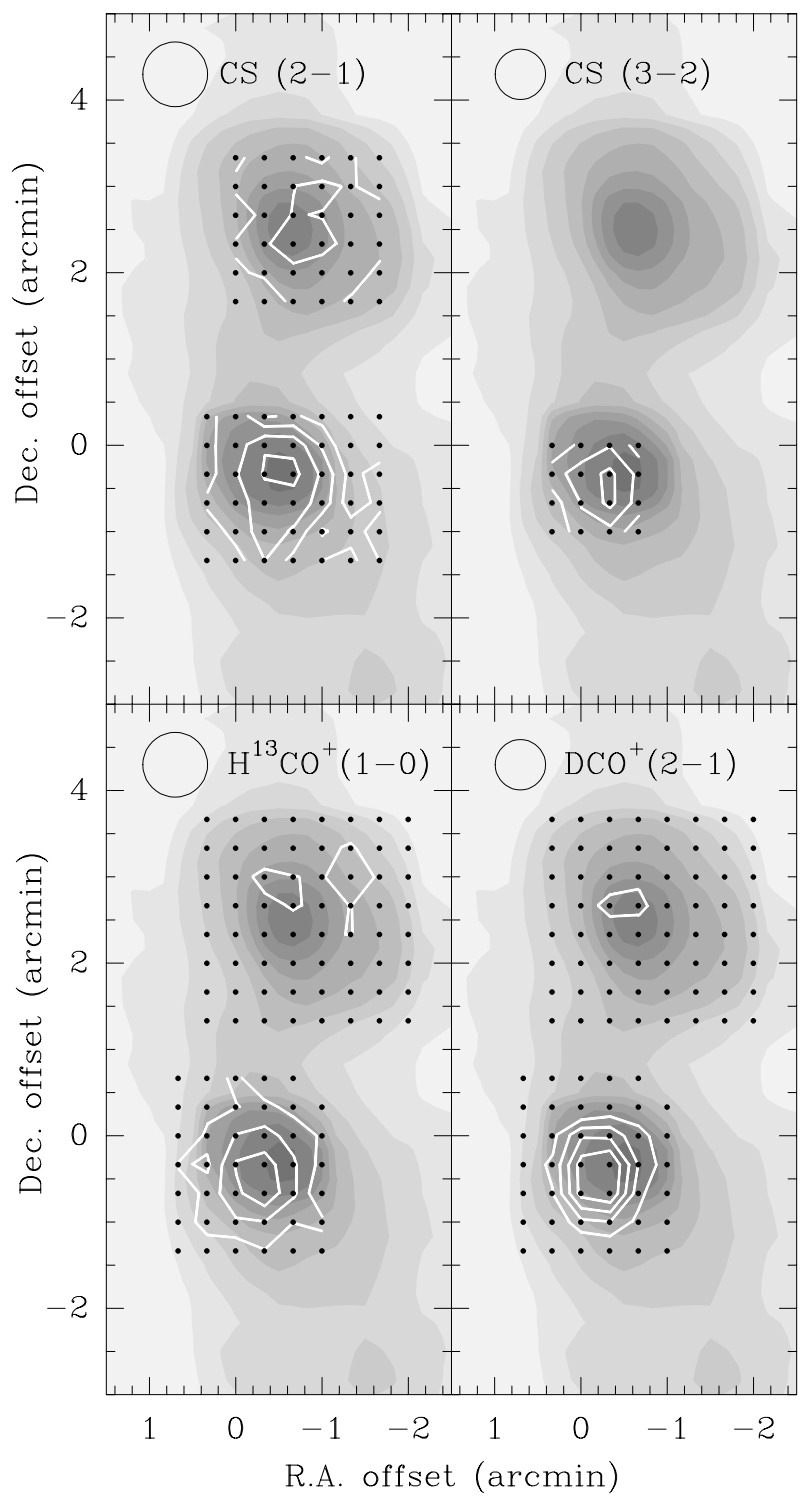

Fig. 4. Contour maps of the observed CS (2-1), CS (3-2), $\mathrm{H}^{13} \mathrm{CO}^{+}(1-0)$, and $\mathrm{DCO}^{+}(2-1)$ distributions in $\mathrm{CG} 12$ superposed on a grey-scale map of the $\mathrm{C}^{18} \mathrm{O}(2-1)$ emission. The positions observed in each molecule are indicated. The corresponding SEST beam size at the observed frequencies is indicated in the upper left corner of each panel. In the CS (2-1) and CS (3-2) maps the lowest contour value is $0.5 \mathrm{~K} \mathrm{~km} \mathrm{~s}^{-1}$ and the increments are $0.5 \mathrm{~K} \mathrm{~km} \mathrm{~s}^{-1}$ and $0.3 \mathrm{~K} \mathrm{~km} \mathrm{~s}^{-1}$, respectively. In the $\mathrm{H}^{13} \mathrm{CO}^{+}(1-0)$ and $\mathrm{DCO}^{+}(2-1)$ maps, the lowest contour value and its increment are $0.15 \mathrm{~K} \mathrm{~km} \mathrm{~s}^{-1}$. The maximum values of the $\mathrm{CS}(2-1), \mathrm{CS}(3-2), \mathrm{H}^{13} \mathrm{CO}^{+}(1-0)$, and $\mathrm{DCO}^{+}(2-1)$ emission are $2.2 \mathrm{~K} \mathrm{~km} \mathrm{~s}^{-1}, 1.3 \mathrm{~K} \mathrm{~km} \mathrm{~s}^{-1}, 0.58 \mathrm{~K} \mathrm{~km} \mathrm{~s}^{-1}$, and $0.77 \mathrm{~K} \mathrm{~km} \mathrm{~s}^{-1}$, respectively. The offset from the map zero position is shown on the axes.

at the position and adding up the multiplied factors. A comparison of the results obtained with PMF analysis to those obtained using the analysis of channel maps and by the use of principal component analysis is given Russeil et al. (2003).

PMF has been applied separately to the north and south parts of CG 12, but there is a small positional overlap between the two areas used in the analysis. The same dataset, shown in Fig. 12, was used in the analysis, i.e., the $\mathrm{C}^{18} \mathrm{O}(2-1)$ data is binned to the same channel width as the $\mathrm{C}^{18} \mathrm{O}(1-0)$ data. The PMF analysis is presented in Appendix A.

\section{Discussion}

The interpretation of the $\mathrm{C}^{18} \mathrm{O}$ data is not as straightforward as one would like and the possible caveats must be considered. The $\mathrm{PMF}$ fit to the observed $\mathrm{C}^{18} \mathrm{O}$ data is good, but which part of the cloud material do the PMF factors trace? The structure of CG 12 and the physical properties of the associated gas can be estimated if the result of the PMF analysis is considered, together with the observed emission from molecules tracing high-density material.

\section{1. $\mathrm{C}^{18} \mathrm{O}$ as a tracer of molecular material}

$\mathrm{C}^{18} \mathrm{O}$ emission is generally considered a good tracer of the large-scale structure of dark clouds and globules. However, $\mathrm{C}^{18} \mathrm{O}$ photodissociation in the cloud envelopes and molecular depletion in the dense and cold cloud cores may restrict the number density interval where $\mathrm{C}^{18} \mathrm{O}$ emission can be used as a direct measure of $\mathrm{H}_{2}$ column density (especially if the LTE approximation is used). Unlike ${ }^{12} \mathrm{CO}$, the $\mathrm{C}^{18} \mathrm{O}$ molecules are not shielded against photodissociation by strong $\mathrm{H}_{2}$ lines, and furthermore, the $\mathrm{C}^{18} \mathrm{O}$ self-shielding is weaker than that of ${ }^{12} \mathrm{CO}$. For $\mathrm{C}^{18} \mathrm{O}$ the self-shielding is most efficient for the two lowest rotational levels with the largest populations. According to Warin et al. (1996), the consequence is that the $J=1-0$ transition becomes thermalized, whereas the higher transitions remain subthermally excited in the cloud envelopes. At the other extreme (pre-stellar cloud cores and protostellar envelopes), the $\mathrm{CO}$ molecule may vanish from the gas phase because of depletion onto dust grains. Other complications in interpreting $\mathrm{C}^{18} \mathrm{O}$ data are the possible strong gradients in the $\mathrm{CO}$ excitation temperature on the line of sight due to heating of the gas by newly born stars and protostellar objects. Time and temperature dependent chemistry, such as deuterium fractionation, also complicates the comparison of $\mathrm{C}^{18} \mathrm{O}$ data with that of other molecular species.

The depletion of molecules on dust grains takes place in the dense, quiescent, and cold molecular cloud cores. The CO and CS molecules are among the first to disappear from the gas phase, but nitrogen-bearing species, such as $\mathrm{N}_{2} \mathrm{H}^{+}$and ammonia, seem to be able to resist depletion (Tafalla et al. 2002). The $\mathrm{N}_{2} \mathrm{H}^{+}$and $\mathrm{DCO}^{+}$lines in $\mathrm{CG} 12-\mathrm{N}$ peak at a velocity of $5.4 \mathrm{~km} \mathrm{~s}^{-1}$ where the $\mathrm{C}^{18} \mathrm{O}$ line emission is weak (Sect. 3.3). It is likely that strong $\mathrm{CO}$ depletion has taken place in the gas traced by these two molecules in CG 12-N.

In $\mathrm{CG} 12-\mathrm{S}$ the $\mathrm{C}^{18} \mathrm{O}$ maximum is spatially offset from the $\mathrm{DCO}^{+}$core. Deuterium fractionation reactions are favoured in cold gas (e.g., Herbst 1982), so the relative abundance of $\mathrm{DCO}^{+}$ is enhanced in cold cloud cores. The relatively strong $\mathrm{DCO}^{+}$ emission observed in CG $12-\mathrm{S}$, the $\mathrm{DCO}^{+}$core, could indicate that fractionation has indeed taken place. If the molecules in CG 12-S were heavily depleted in the cold $\mathrm{DCO}^{+}$core, one would not expect $\mathrm{CS}(3-2)$ or $\mathrm{H}^{13} \mathrm{CO}^{+}$to outline the core like they do (also $\mathrm{DCO}^{+}$will be finally depleted).

The observed ${ }^{12} \mathrm{CO}(1-0)$ and $(2-1)$ line temperatures in CG 12-S (Fig. 3) are high. The lines are self reversed, so the actual line peak temperatures must be even higher. This indicates that the $\mathrm{CO}$ excitation temperature is in excess of $30 \mathrm{~K}$ in the part of the cloud that is traced by the observed ${ }^{12} \mathrm{CO}$ emission. White (1993) suggests that either h4636 or IRAS 13547-3944 is the heating source. The ${ }^{12} \mathrm{CO}$ and ${ }^{13} \mathrm{CO}$ optical depth is high and, unlike $\mathrm{C}^{18} \mathrm{O}$, these $\mathrm{CO}$ isotopoloques are likely to trace only the surface of the molecular cloud associated with CG 12 . The observed $\mathrm{C}^{18} \mathrm{O}(3-2) T_{\mathrm{MB}}$ peak temperature of $11 \mathrm{~K}$ 


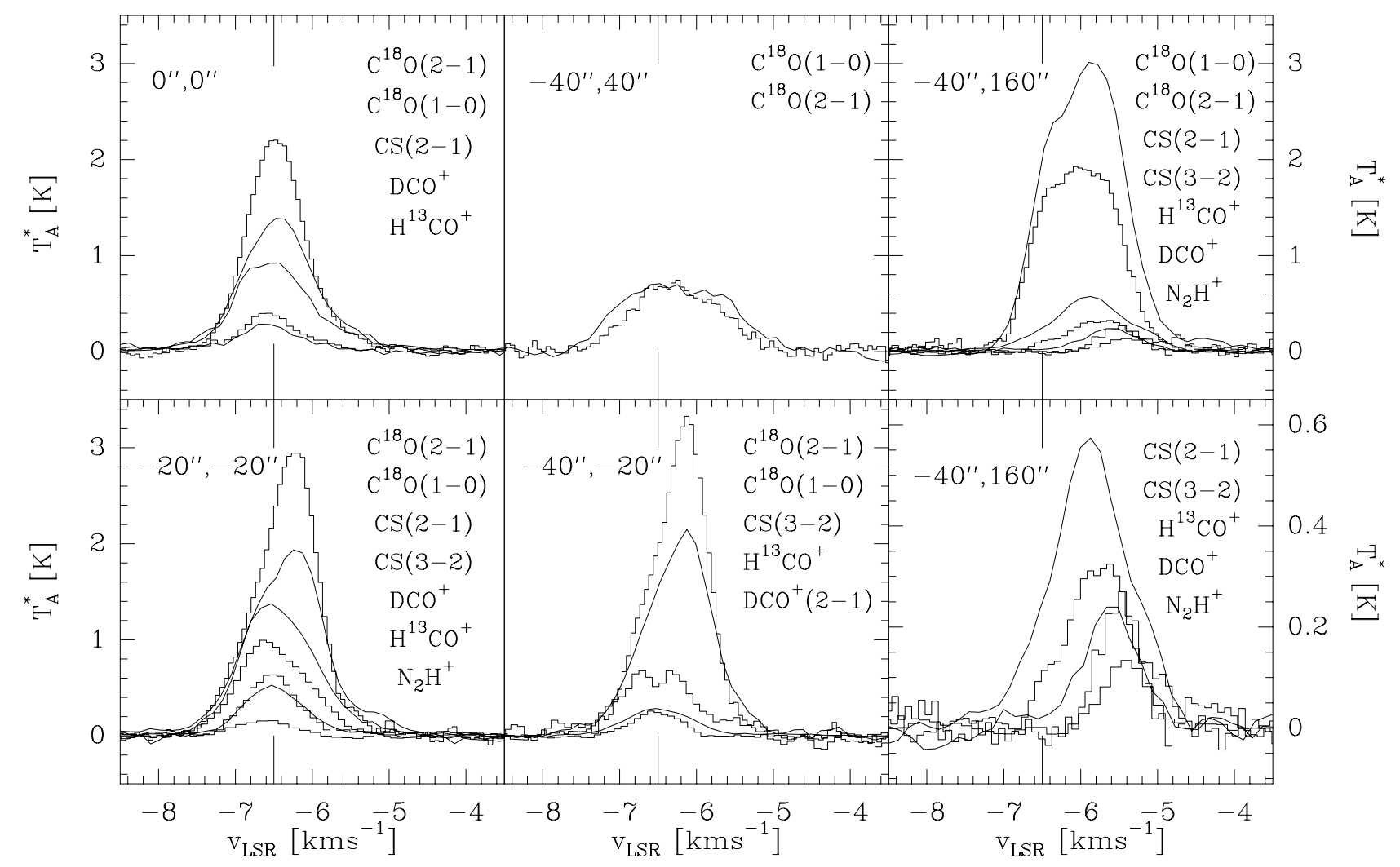

Fig. 5. Spectra of the $\mathrm{C}^{18} \mathrm{O}$ and molecules that are sensitive to number density towards the same positions as shown in Fig. 3. Only the unblended hyperfine $\mathrm{N}_{2} \mathrm{H}^{+}(1-0)\left(\mathrm{F}_{1}, F=1,0 \rightarrow 1,2\right)$ component is shown. The velocity tick indicates a velocity of $-6.5 \mathrm{~km} \mathrm{~s}^{-1}$. The $\mathrm{C}^{18} \mathrm{O}(1-0), \mathrm{CS}(2-1)$ and $\mathrm{H}^{13} \mathrm{CO}^{+}$lines are plotted using a continuous line. The panel lower right is a blowout of the upper right panel showing only the lines tracing high number density.

in $\mathrm{CG} 12-\mathrm{S}$ also points at a high $\mathrm{C}^{18} \mathrm{O}$ excitation temperature (Haikala et al. 2006). However, the observed relative $\mathrm{C}^{18} \mathrm{O}(2-1)$ and $(1-0)$ line intensities in CG $12-\mathrm{S}$ are not compatible with $\mathrm{C}^{18} \mathrm{O} T_{\mathrm{ex}}$ values higher than $20 \mathrm{~K}$.

\subsection{PMF: the interpretation}

One should be cautious in interpreting the PMF results. Even though the fit to the $\mathrm{C}^{18} \mathrm{O}(1-0)$ and $(2-1)$ data is good, all the PMF factors do not necessarily describe real cloud components. The structure of the cloud can, however, be discussed with some confidence when the PMF fit results are considered with the information provided by other available molecular lines, $\mathrm{mm}$ continuum, and NIR-FIR data.

\subsubsection{CG 12-S}

The location of the CG 12-S $\mathrm{C}^{18} \mathrm{O}(2-1)$ PMF factor maxima relative to the NIR cone (and the mm continuum source) in the centre of the $\mathrm{DCO}^{+}$core is shown in Fig. 10. From East to West the factors are $1 \mathrm{~s}, 2 \mathrm{~s}$, and $3 \mathrm{~s}$. The centres of the maxima differ in position by about one SEST beam size at $220 \mathrm{GHz}, 24^{\prime \prime}$.

The data would seem to imply that CG $12-\mathrm{S}$ is fragmented into three individual cores. If this were the case, one would expect that the $2 \mathrm{~s}$ factor would coincide with the $\mathrm{DCO}^{+}$core because the $2 \mathrm{~s}$ centre of line velocity is the same as that of $\mathrm{DCO}^{+}$. Even though the $3 \mathrm{~s}$ factor is the strongest in CG $12-\mathrm{S}$, it is detected only as an asymmetry in the $\mathrm{DCO}^{+}$and CS lines in Figs. 5 and 6. $\mathrm{CO}$ is ubiquitous and easily excited, so that it can be detected at much lower densities than the high-density tracers

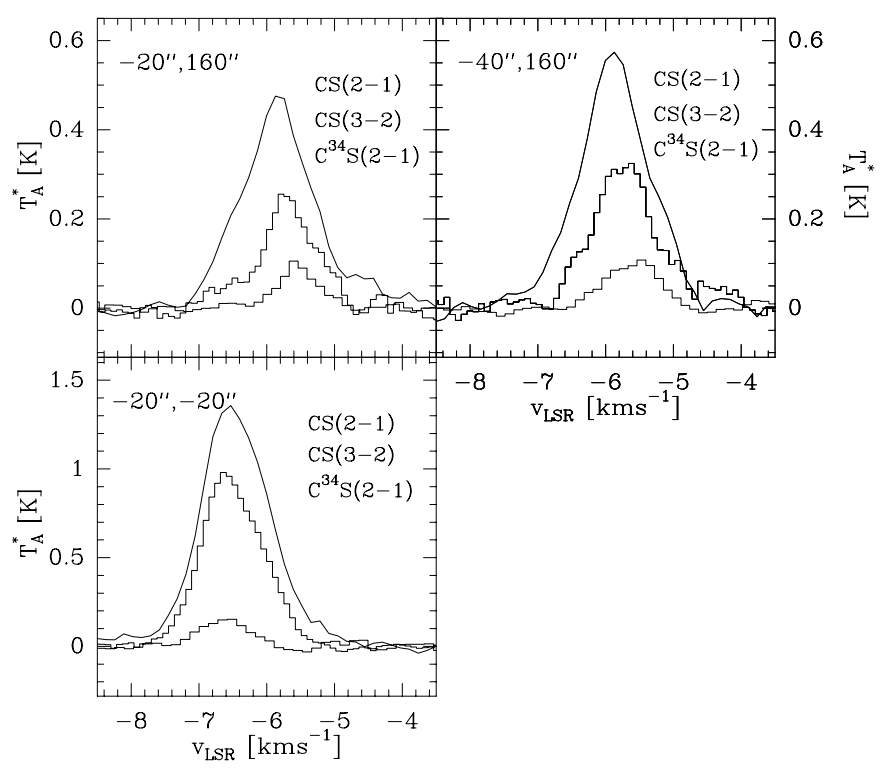

Fig. 6. CS (2-1), (3-2) and $C^{34} S(1-0)$ spectra observed in the direction of CG 12-N (the two upper panels) and CG 12-S (the lower panel).

$\mathrm{DCO}^{+}$and CS (3-2), which trace the $\mathrm{DCO}^{+}$core. The bulk of the observed $\mathrm{C}^{18} \mathrm{O}$ emission may have its origin in that part of the cloud where the density is lower and the excitation temperature higher than in the $\mathrm{DCO}^{+}$core.

This leads to a model where most of the observed $\mathrm{C}^{18} \mathrm{O}$ emission instead traces either the surface of the dense and cold cloud core (the $\mathrm{DCO}^{+}$core) or a separate, adjacent cloud 

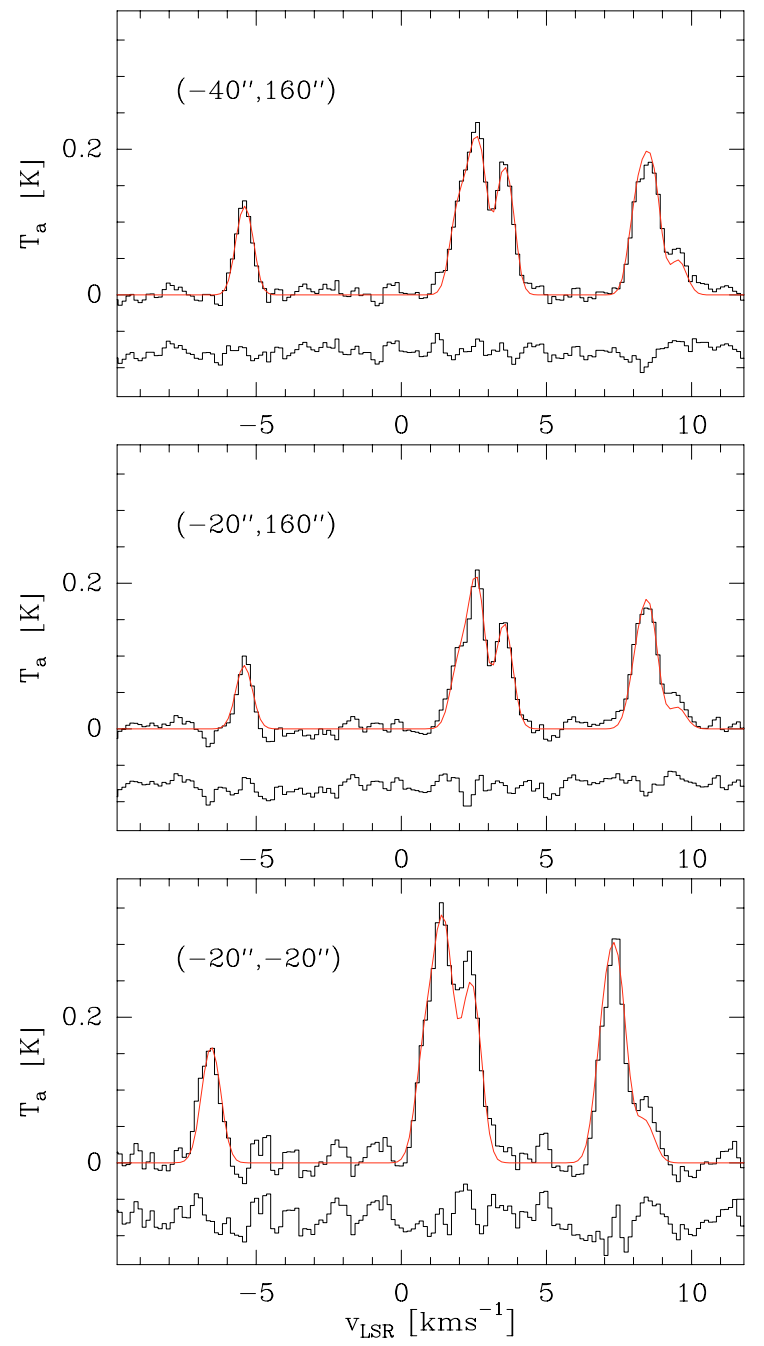

Fig. 7. $\mathrm{N}_{2} \mathrm{H}^{+}(1-0)$ spectra observed in the direction of CG 12-N (the two upper panels) and CG 12-S (the lower panel). The sevencomponent hyperfine structure fit and the resulting residuals are shown.

component, rather than the core itself. The observed CS (2-1) distribution, which is similar to $\mathrm{C}^{18} \mathrm{O}$ in $\mathrm{CG} 12-\mathrm{S}$ (Fig. 4), is in accord with this model. Much of the observed CS (2-1) emission is known to originate in cloud envelopes and not in the dense cores. The CS (3-2) effective critical density is higher than that of CS (2-1), therefore it traces the dense gas deeper in the cloud than CS $(2-1)$.

The possible interaction of the collimated molecular outflow detected by White (1993) with the cloud core further complicates the interpretation of the molecular line data. The centre of the outflow is located in the direction of the $\mathrm{DCO}^{+}$core, and it is not unlikely that the outflow can produce weak $\mathrm{C}^{18} \mathrm{O}$ line wings and that it can raise the $\mathrm{CO}$ excitation temperature locally. Weak line wings are also observed in the CS (2-1) line in Fig. 5. It is argued that the weak $\mathrm{C}^{18} \mathrm{O}$ red and blue shifted line wing emission near the $\mathrm{DCO}^{+}$core is produced by the interaction of the collimated molecular outflow with the parent cloud. The line wings would be described by the PMF factors $1 \mathrm{~s}$ and $4 \mathrm{~s}$. For the latter factor this would consist only of the emission immediately to the west of the $\mathrm{DCO}^{+}$core.

The CG 12-S C ${ }^{18} \mathrm{O}$ (3-2) map in Haikala et al. (2006) covers only the very centre of $\mathrm{CG} 12-\mathrm{S}$. The $\mathrm{C}^{18} \mathrm{O}(3-2)$ line peak velocity and the intensity distribution is in accordance with the elongated shape of the 3 s component in Fig. 10. The maximum

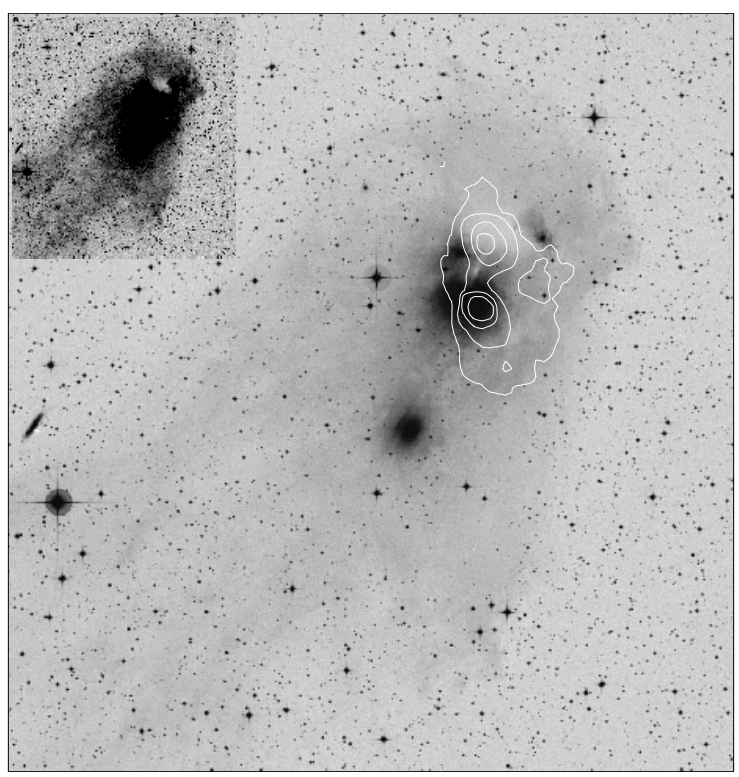

Fig. 8. Contour map of the $\mathrm{C}^{18} \mathrm{O}(2-1)$ emission superposed on the optical (DSS blue) image of NGC 5367. The image is also shown in the inset but using an intensity scale that brings out the surface emission better. The linear size of the image is $32^{\prime}$ by $32^{\prime}$.

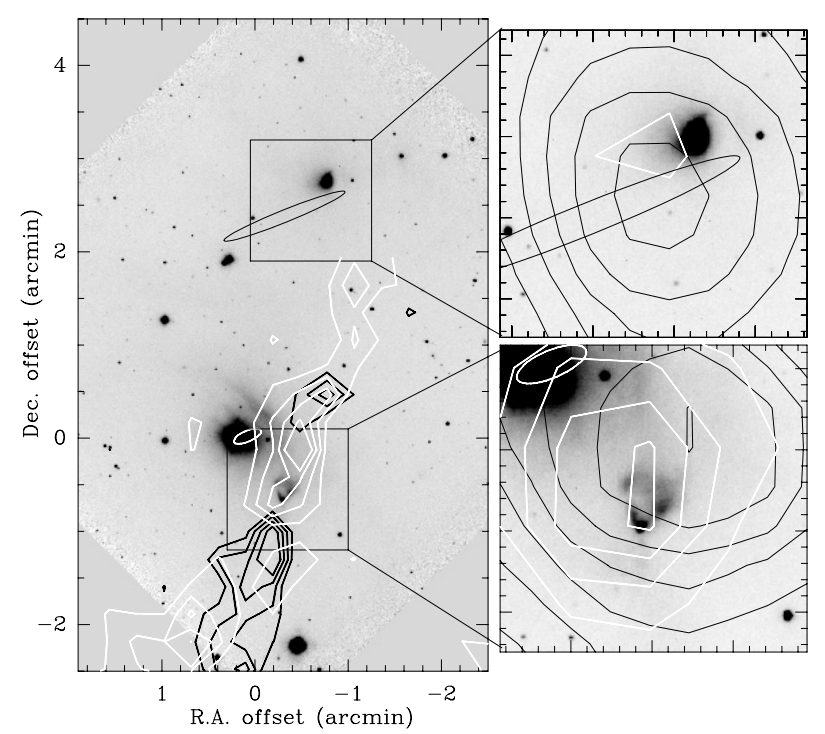

Fig. 9. $K$ s-band image of CG-12 (Haikala 2007, in preparation). Contours of the blue (white contours) and redshifted (black) ${ }^{12} \mathrm{CO}(2-1)$ line-wing emission (White 1993) are also shown. The two insets show the CG 12-S and CG 12-N regions in detail. Superposed are the contours of $\mathrm{C}^{18} \mathrm{O}(2-1)$ (black) and $\mathrm{DCO}^{+}$(white) emission. The positional uncertainty ellipses of the IRAS point source's IRAS 13547-3944 in CG 12-S and IRAS 13546-3941 in CG 12-N are also shown.

of the $3 \mathrm{~s}$ factor is compact and lies on the outflow axis only $\sim 20^{\prime \prime}$ away from the apex of the NIR cone (Fig. 9), the putative position of the outflow driving source. This suggests, that the high $3 \mathrm{~s} \mathrm{C}^{18} \mathrm{O}$ line intensities and the molecular outflow could be connected.

\subsection{2. $\mathrm{CG} 12-\mathrm{N}$}

PMF produces a seemingly straightforward solution for CG 12-N. However, the available data from molecules other 


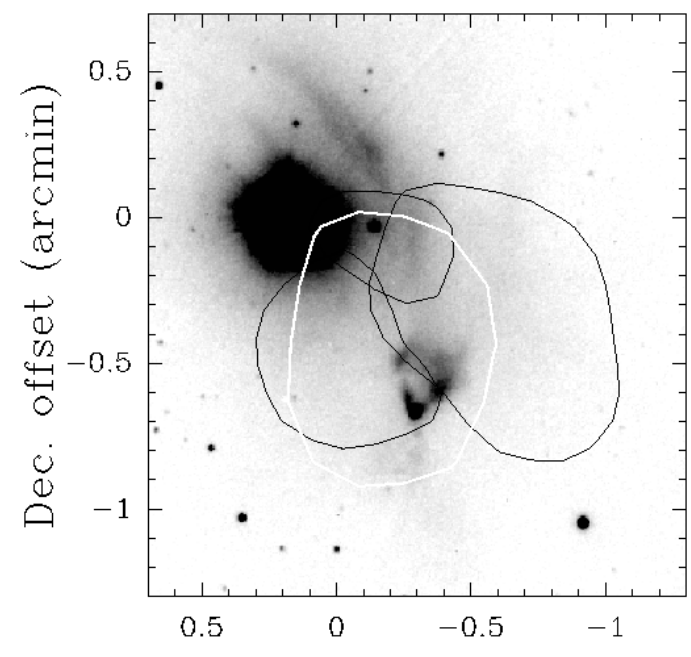

R.A offset (arcmin)

Fig. 10. The $\mathrm{CG} 12-\mathrm{S} \mathrm{C}^{18} \mathrm{O}(2-1) 1 \mathrm{~s}, 2 \mathrm{~s}$, and $3 \mathrm{~s}$ (from East to West) factor peak emission positions $\left(0.8 \mathrm{~K} \mathrm{~km} \mathrm{~s}^{-1}\right.$ contours $)$ and $\mathrm{DCO}^{+}$core position (white) superposed on the SOFI Ks band image. Offsets from the map's zero position are shown in arcminutes. The SEST beam at the $\mathrm{C}^{18} \mathrm{O}(2-1)$ frequency is $0.37 \mathrm{arcmin}$.

than $\mathrm{C}^{18} \mathrm{O}$ and the $1.2 \mathrm{~mm}$ continuum emission deny such a simple solution. As argued in Sect. 6.1, it is likely that the cloud component traced by $\mathrm{DCO}^{+}$and $\mathrm{N}_{2} \mathrm{H}^{+}$is heavily depleted. If this is the case, $\mathrm{C}^{18} \mathrm{O}$ only probes the undepleted part of $\mathrm{CG} 12-\mathrm{N}$.

\subsection{Clouds's physical properties}

A straightforward division of the CG 12 molecular cloud into three homogeneous components, CG 12-N, CG 12-S, and $\mathrm{CG} 12-\mathrm{SW}$, is not possible. The good velocity resolution and the high signal-to-noise ratio of the data allows one to divide the $\mathrm{C}^{18} \mathrm{O}$ data into separate components. However, the derivation of the cloud or core physical properties calls for a detailed threedimensional non-LTE model that accounts for both the molecular depletion, the varying density, and excitation conditions. Such a model is beyond the scope of this paper and will be left for the future. The LTE-approximation approach is used instead of a sophisticated model to make a zeroth-order estimate of the masses of the three $\mathrm{C}^{18} \mathrm{O}$ maxima, CG 12-N, CG 12-S, and CG 12-SW. An average $\mathrm{C}^{18} \mathrm{O}$ excitation temperature for each maximum is estimated using the observed relative $\mathrm{C}^{18} \mathrm{O}(2-1)$ and $(1-0)$ line intensities.

\subsubsection{Mass and column-density estimation}

The observed $T_{\mathrm{A}}^{*}$ line temperatures were converted into main beam temperatures using the beam efficiencies in Table 1. The $\mathrm{C}^{18} \mathrm{O}$ excitation temperatures were estimated from the $\mathrm{C}^{18} \mathrm{O}(1-0)$ and $(2-1)$ data by assuming optically thin $\mathrm{C}^{18} \mathrm{O}$ emission and LTE. This assumes that the observed emission in both transitions originates in the same volume of gas at a constant excitation temperature. The observed $\mathrm{C}^{18} \mathrm{O}$ line $T_{\mathrm{MB}}(2-1) / T_{\mathrm{MB}}(1-0)$ ratio is 1.8 in CG $12-\mathrm{S}$, compatible with an excitation temperature near $15 \mathrm{~K}$. In CG $12-\mathrm{N}$ and CG 12-SW, this ratio is one or less, indicating excitation temperatures of the order of $10 \mathrm{~K}$.

The masses of CG 12-N, CG 12-S, and CG 12-SW are calculated without dividing them into smaller components. The spectra between declination offsets (including the limits) $-120^{\prime \prime}$ and $+60^{\prime \prime}$ were assigned to CG $12-\mathrm{S}$. The spectra above and below these limits were assigned to CG 12-N and CG 12-SW, respectively. An average $\mathrm{C}^{18} \mathrm{O}$ excitation temperature of $10 \mathrm{~K}$ is now assumed for CG $12-\mathrm{N}$ and CG $12-\mathrm{SW}$ and $15 \mathrm{~K}$ for CG 12-S. The adopted $\mathrm{C}^{18} \mathrm{O}$ abundance is $2.0 \times 10^{-7}$. This results in calculated total masses of 34,96 , and $110 M_{\odot}$ for CG $12-\mathrm{SW}$, CG $12-S$ and CG $12-\mathrm{N}$, respectively, when $\mathrm{C}^{18} \mathrm{O}(1-0)$ data is used. If $\mathrm{C}^{18} \mathrm{O}(2-1)$ data is used the masses are 14, 49, and 53 $M_{\odot}$. The maximum $T_{\mathrm{MB}}$ line integrals can be used to estimate the $\mathrm{H}_{2}$ column densities in the corresponding beams. The calculated maximum column densities in the $\mathrm{C}^{18} \mathrm{O}(1-0)$ beam are $1.3 \times$ $10^{22}, 1.8 \times 10^{22}$, and $2.7 \times 10^{22} \mathrm{~cm}^{-2}$ for CG $12-\mathrm{SW}$, CG $12-\mathrm{S}$, and $\mathrm{CG} 12-\mathrm{N}$, respectively. For the $\mathrm{C}^{18} \mathrm{O}(2-1)$ beam the corresponding values are $6.4 \times 10^{21}, 1.6 \times 10^{22}$, and $1.8 \times 10^{22} \mathrm{~cm}^{-2}$.

The masses calculated from the $\mathrm{C}^{18} \mathrm{O}(1-0)$ data are approximately twice higher than from the $(2-1)$ data. The LTE approximation assumes that all the $\mathrm{C}^{18} \mathrm{O}$ rotational states are thermalized. However, according to Warin et al. (1996) only the lowest $\mathrm{C}^{18} \mathrm{O}$ rotational state is thermalized in dark clouds, and the higher states are subthermally excited. The subthermal excitation would be stronger in the relatively low-density cloud envelope than in the dense core. The subthermal level population leads to an underestimation of the cloud mass when calculated from the $\mathrm{C}^{18} \mathrm{O}(2-1)$ data. This could be a partial explanation for the large discrepancy between the masses calculated using $\mathrm{C}^{18} \mathrm{O}(1-0)$ and $(2-1)$ data.

Strong $\mathrm{C}^{18} \mathrm{O}(3-2)$ emission (maximum $T_{\mathrm{MB}} \sim 11 \mathrm{~K}$ ) distributed in a similar way to the $3 \mathrm{~s}$ PMF factor was detected by Haikala et al. (2006) in the centre of CG 12-S. The $\mathrm{C}^{18} \mathrm{O}(3-2)$ data was modelled with a compact $\left(60^{\prime \prime}\right.$ to $80^{\prime \prime}$ diameter) and hot $\left(80 \mathrm{~K} \lesssim T_{\text {ex }} \lessgtr 200 \mathrm{~K}\right)$ optically-thin clump of $\sim 1.6 M_{\odot}$. The high temperature was derived from the $T_{\mathrm{MB}}\left(\mathrm{C}^{18} \mathrm{O}(3-2)\right) / T_{\mathrm{MB}}\left(\mathrm{C}^{18} \mathrm{O}(2-1)\right)$ ratio. However, the $T_{\mathrm{MB}}\left(\mathrm{C}^{18} \mathrm{O}(2-1)\right) / T_{\mathrm{MB}}\left(\mathrm{C}^{18} \mathrm{O}(1-0)\right)$ ratio for the CG $12-\mathrm{S}$ PMF factor $3 \mathrm{~s}$ is not compatible with such a high temperature. This could be due to, e.g., contribution from a subthermally excited cool cloud envelope to the $\mathrm{C}^{18} \mathrm{O}(1-0)$ emission. The LTE mass calculated from the $\mathrm{C}^{18} \mathrm{O}(2-1) 3 \mathrm{~s}$ component within the area modelled in Haikala et al. (2006) is $4.1 M_{\odot}$ when a $T_{\text {ex }}$ of $15 \mathrm{~K}$ is assumed. The discrepancy in the calculated excitation temperatures and masses highlights the uncertainties when LTE approximation is used and only data of the two lowest $\mathrm{C}^{18} \mathrm{O}$ transitions are available. In contrast to CG $12-\mathrm{S}$, the $\mathrm{C}^{18} \mathrm{O} T_{\mathrm{ex}}$ and the LTE mass of CG $12-\mathrm{N}$ correspond well to the modelled values using the three transitions (Haikala et al. 2006).

\subsection{Summary}

The analysis of the spectral lines presented above deliver a complicated picture of CG 12. Even though the spectral lines are relatively narrow, the analysis reveals a rich structure in line shape and velocity. Probable depletion of molecules on dust grains in CG 12-N further complicates the interpretation. The cloud parameters derived using the LTE analysis are highly uncertain. However, if the molecular-line observations are combined with the available optical, NIR, FIR, and mm continuum data, the cloud structure can be discussed with some confidence.

\subsubsection{CG 12-N}

CG 12-N harbours a compact, cold mm source, and the detected relatively weak molecular emission in high-density tracers is 
probably associated with this source. Much of the molecular material associated with this cloud component is likely to be highly depleted onto dust. The observed strong $\mathrm{C}^{18} \mathrm{O}$ emission towards CG 12-N therefore originates in the envelope of this depleted core or in a separate entity seen in the same line of sight. The ${ }^{12} \mathrm{CO}$ observed in the direction of CG $12-\mathrm{N}$ has line-wing emission indicating molecular outflow. It is not known if this outflow is connected to the outflow in CG $12-\mathrm{S}$ or if it is local and originates in $\mathrm{CG} 12-\mathrm{N}$.

\subsubsection{CG 12-S}

The bulk of the observed $\mathrm{C}^{18} \mathrm{O}$ emission does not trace the gas associated with the compact cloud core detected in $\mathrm{H}^{13} \mathrm{CO}^{+}$, $\mathrm{DCO}^{+}$and $\mathrm{CS}(3-2)$ lines. Most likely the $\mathrm{C}^{18} \mathrm{O}$ emission traces only the surface of this core. The moderate $\mathrm{C}^{18} \mathrm{O}$ line wing emission, probably due to interaction of the highly collimated molecular outflow with the surrounding gas, complicates the interpretation even further.

The molecular line data presented in this paper, combined with the molecular outflow data from White (1993), the NIR imaging, and mm dust continuum data (Haikala 2007, in preparation), shows that the outflow centre coincides with the $\mathrm{mm}$ continuum source and the NIR cone in the centre of the $\mathrm{DCO}^{+}$ core. The strong point source IRAS 13547-3944 is offset from the mm source and from h4636. This point source could, however, be the driving source for the strong redshifted outflow lobe north of CG 12-S.

\subsubsection{CG 12-SW}

CG12-SW is inconspicuous when compared to the two stronger $\mathrm{C}^{18} \mathrm{O}$ maxima. No signs of star formation have been found in its direction, and it is therefore either still in pre-star formation phase or its density-temperature structure is such that no star formation will take place. The arc-like feature that connects CG $12-\mathrm{S}$ and CG $12-\mathrm{SW}$ at velocities from $-6.6 \mathrm{~km} \mathrm{~s}^{-1}$ to $-6.2 \mathrm{~km} \mathrm{~s}^{-1}$ in Fig. 11 suggests that CG 12-SW might be related to $\mathrm{CG} 12-\mathrm{S}$.

\section{Conclusions}

We have performed a detailed, high signal-to-noise ratio, mmline study of CG 12 in various molecular transitions, principally of $\mathrm{C}^{18} \mathrm{O}(1-0)$ and $\mathrm{C}^{18} \mathrm{O}(2-1)$, as well as in molecular lines probing dense material, with the following results:

1. The $\mathrm{C}^{18} \mathrm{O}$ line emission is distributed in a $10^{\prime}$ NorthSouth elongated lane with two strong, compact maxima, CG 12-N and CG 12-S, and a weaker maximum, CG 12-SW.

2. High-density tracers CS $(2-1),(3-2), \mathrm{DCO}^{+}$, and $\mathrm{H}^{13} \mathrm{CO}^{+}$are detected in both strong $\mathrm{C}^{18} \mathrm{O}$ maxima. Emission from these molecules is weak in CG $12-\mathrm{N}$, but in CG $12-\mathrm{S}$ it defines a compact core (referred to as $\mathrm{DCO}^{+}$core) that is spatially offset from the $\mathrm{C}^{18} \mathrm{O}$ maximum.
3. The emission from the high-density tracers in CG $12-\mathrm{N}$ takes place at a velocity where emission from $\mathrm{C}^{18} \mathrm{O}$ is weak. The molecules associated with the cloud component detected in high-density tracers are likely to be heavily depleted.

4. Positive matrix factorization was applied to study the cloud $\mathrm{C}^{18} \mathrm{O}$ fine-scale structure. The observed strong $\mathrm{C}^{18} \mathrm{O}$ emission in CG $12-\mathrm{N}$ (PMF factor $2 n$ ) originates in the envelope of the depleted cloud component or in a separate entity seen in the same line of sight. In CG 12-S the most intense PMF factor $3 s$ traces warm gas on the surface of the $\mathrm{DCO}^{+}$core or a separate adjacent cloud component.

5. The driving source of the collimated molecular outflow detected by White (1993) lies in the $\mathrm{DCO}^{+}$core.

6. The average $\mathrm{C}^{18} \mathrm{O}$ LTE mass is $\sim 80 M_{\odot}$ for $\mathrm{CG} 12-\mathrm{N}$, $\sim 70 M_{\odot}$ for CG 12-S, and $\sim 20 \quad M_{\odot}$ for CG 12-SW. These numbers can only be considered as a zerothorder estimate because of the uncertainty in defining the $\mathrm{C}^{18} \mathrm{O}$ excitation temperature and possible molecular depletion in the $\mathrm{C}^{18} \mathrm{O}$ maxima.

7. If the distance to $\mathrm{CG} 12,630 \mathrm{pc}$, is correct, the linear size and the mass of this cometary globule approaches that of a typical low-mass star-forming region like e.g. Chamaeleon I.

Acknowledgements. We thank Bo Reipurth for critically reading the manuscript and for very useful comments that helped to improve this paper. We also thank Mika Juvela and Kalevi Mattila for helpful discussions and Pentti Paatero for providing the PMF code. Data retrieved from the Canadian Astronomy Data Centre were used to produce the $\mathrm{CO}$ outflow contours in Fig. 9. The Canadian Astronomy Data Centre is operated by the Herzberg Institute of Astrophysics, National Research Council of Canada.

\section{References}

Arnal, E. M., Bajaja, E., Larrarte, J. J., Morras, R., \& Pöppel, W. G. L. 2000, A\&AS, 142, 35

Haikala, L. K., Harju, J., Mattila, K., \& Toriseva, M. 2005, A\&A, 431, 149

Haikala, L. K., Juvela, M., Harju, J., et al. 2006, A\&A, 454, L71

Hartman, D., \& Burton, W. B. 1997, Atlas of Galactic Neutral Hydrogen (Cambridge University Press)

Hawarden, T. G., \& Brand, P. W. J. L. 1976, MNRAS, 175, 19P

Herbst, E. 1982, A\&A, 111, 76

Herschel, J. F. W. 1847, Results of Astronomical Observations made during the years 1834, 5, 6, 7, 8 at the Cape of Good Hope (London: Smith, Elder) Juvela, M., Lehtinen, K., \& Paatero, P. 1996, MNRAS, 280, 616

Kalberla, P. M. W., Burton, W. B., Hartman, D., et al. 2005, A\&A, 440, 775

Maheswar, G., Manoj, P., \& Bhatt, H. C. 2004, MNRAS, 355, 1272

Odenwald, S. F. 1988, ApJ, 325, 320

Rawlings, J. M. C., Taylor, S. D., \& Willimas, D. A. 2000, MNRAS, 313, 461 Reipurth, B. 1983, A\&A, 117, 183

Reipurth, B., Nyman, L- ̊, \& Chini, R. 1996, A\&A, 314, 258

Rohlfs, K., \& Wilson, T. L. 1999, Tools of Radio Astronomy (Berlin: Springer)

Russeil, D., Juvela, M., Lehtinen, K., Mattila, M., \& Paatero, P. 2003, A\&A, 409, 135

Tafalla, M., Myers, P. C., Caselli, P., Walmsley, C. M., \& Conito, C. 2002, ApJ, 569,815

Santos, N. C., Yun, J. L., Santos, S. A., \& Marreiros, R. G. 1998, AJ, 116, 1376

Warin, S., Benayoun, J. J., \& Viala, Y. P. 1996, A\&A, 308, 535

White, G. 1993, A\&A, 274, L33

Williams, P. M., Brand, P. W. J. L., Longmore, A. J., \& Hawarden, T. G. 1977, MNRAS, 181, 179

Yonekura, Y., Hayakawa, T., Mizuno, N., et al. 1999, PASJ, 51, 837 
L. K. Haikala and M. Olberg: The structure of the cometary globule CG 12, Online Material p 1

\section{Online Material}


L. K. Haikala and M. Olberg: The structure of the cometary globule CG 12, Online Material $p 2$

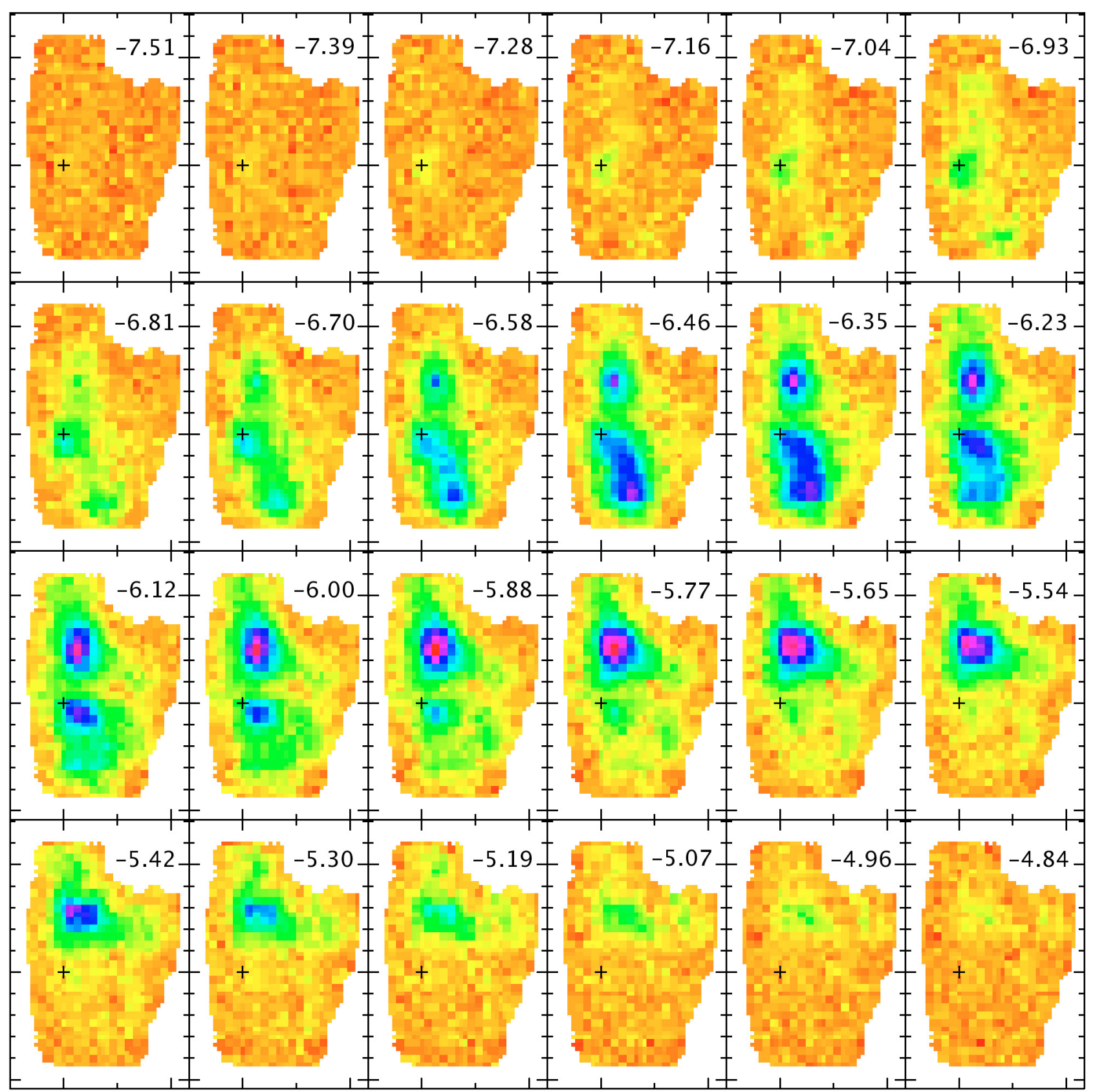

Fig. 11. $T_{\mathrm{A}}^{*}$ channel map of the $\mathrm{C}^{18} \mathrm{O}(1-0)$ emission in CG 12. The LSR velocity is indicated in the upper right corners of the panels. Each pixel corresponds to a single observed position. The highest intensity in the panels is $\sim 3.0 \mathrm{~K}$. The cross in the panels is located in the map's centre position, $13^{\mathrm{h}} 57^{\mathrm{m}} 43^{\mathrm{s}} \cdot 1,-39^{\circ} 58^{\prime} 43^{\prime \prime} \cdot 3(\mathrm{~J} 2000)$. 
L. K. Haikala and M. Olberg: The structure of the cometary globule CG 12, Online Material $p 3$

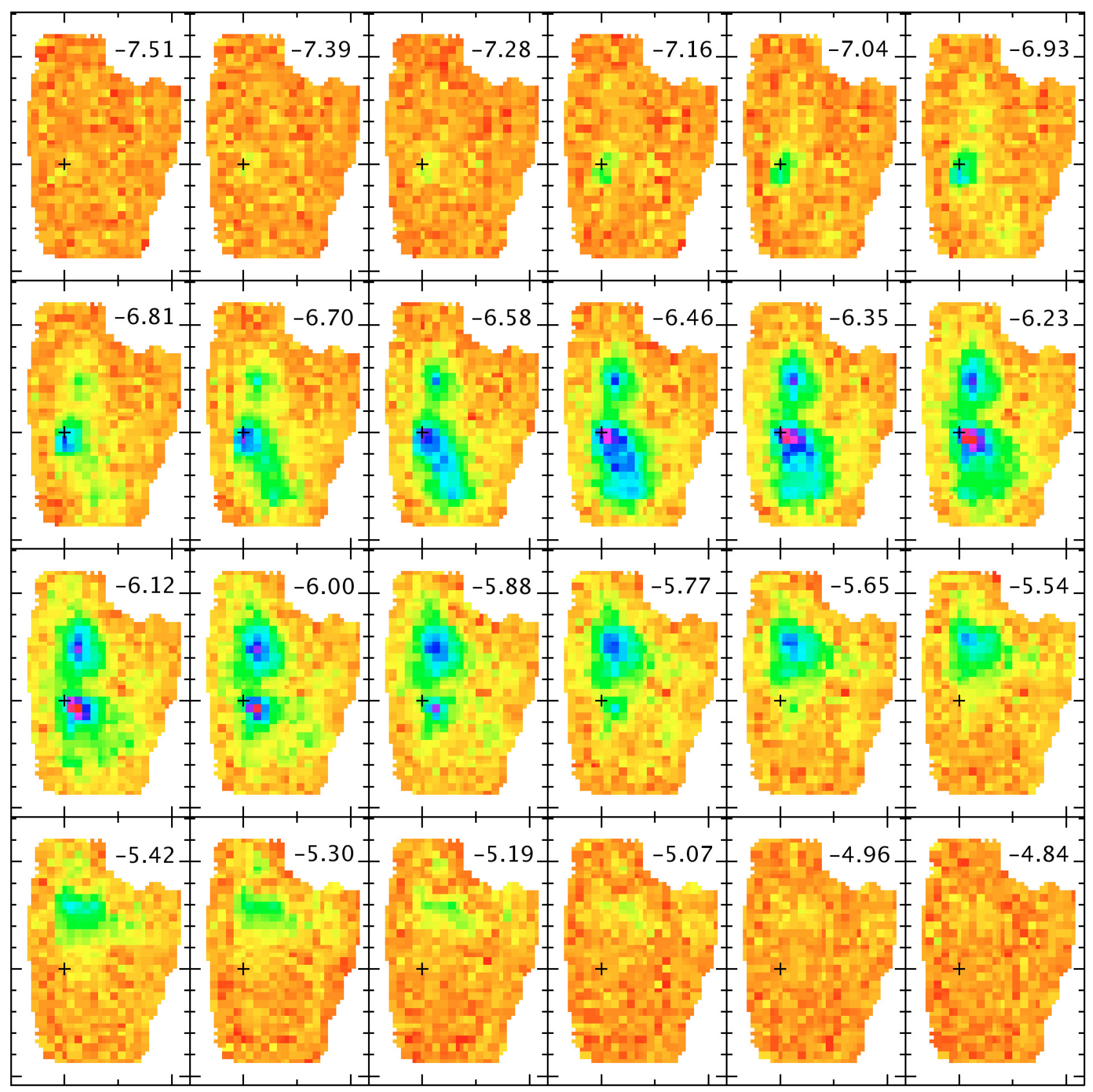

Fig. 12. As Fig. 11 but for the $\mathrm{C}^{18} \mathrm{O}(2-1)$ transition. The data shown in the figure is binned to the same channel width as the (1-0) data, $0.116 \mathrm{~km} \mathrm{~s}^{-1}$. The colour scale is the same as in Fig. 11 . 
L. K. Haikala and M. Olberg: The structure of the cometary globule CG 12, Online Material p 4
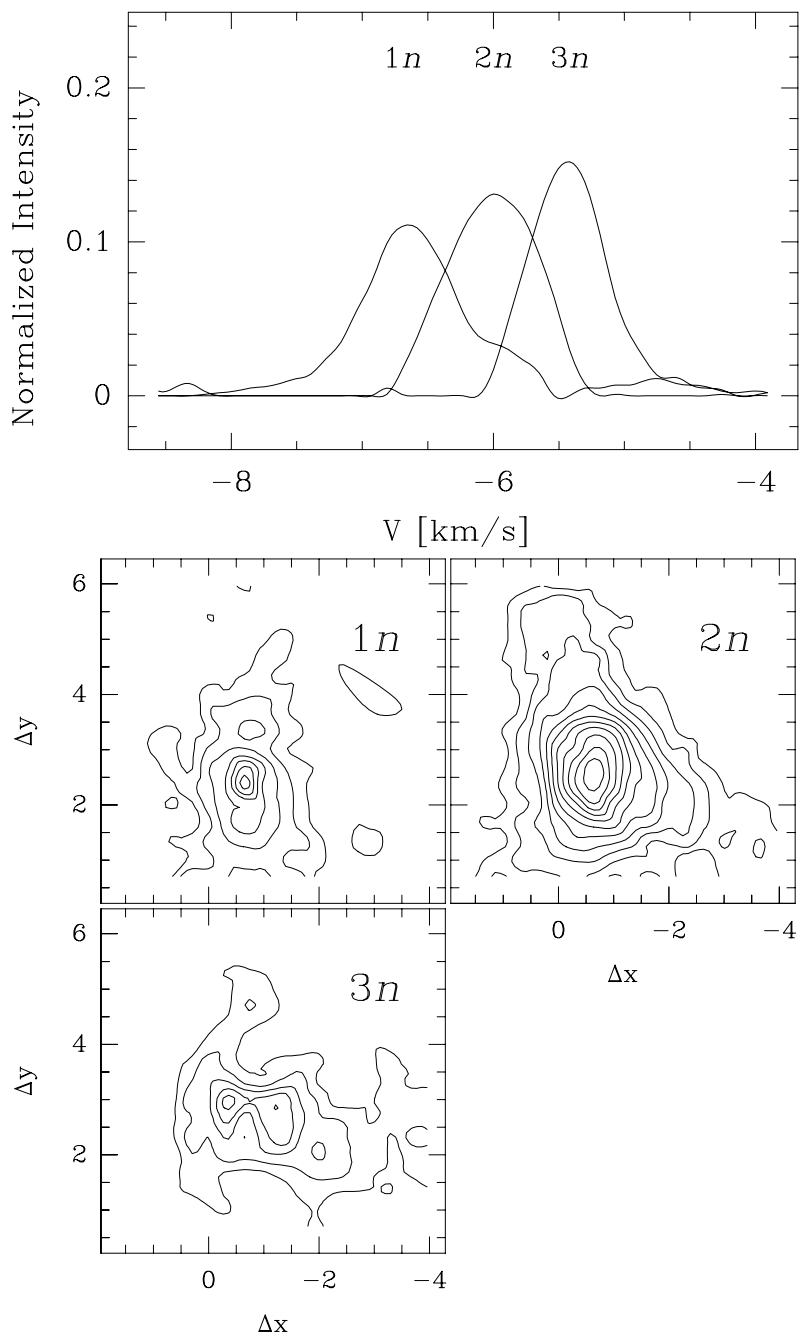

Fig. A.1. Upper ccc panel: the basic spectral profiles (factors) calculated by the PMF in CG 12-N (three factor fit), $\mathrm{C}^{18} \mathrm{O}(1-0)$ data. Lower panels: maps of the weights of the basic factors. The lowest contour level and increment are $0.2 \mathrm{~K} \mathrm{~km} \mathrm{~s}^{-1}$. Offsets from the centre position of the original $\mathrm{C}^{18} \mathrm{O}$ map are shown in arcminutes on the $x$ and $y$ axes.

\section{Appendix A: Positive matrix factorization analysis of CG 12}

\section{A.1. CG 12-N}

The results of the PMF, assuming three factors, to observed $\mathrm{C}^{18} \mathrm{O}(1-0)$ and $(2-1)$ data in $\mathrm{CG} 12-\mathrm{N}$ are shown in Figs. A.1 and A.2. The uppermost panels show the three fitted PMF factors. The area under each factor is normalized to one. The histogram superposed on the rightmost factor in Fig A.2 indicates the velocity resolution of the input data. The intensity distribution of the PMF factors in CG 12-N is shown in the lower three panels.

The PMF reproduces the velocity structure displayed in Figs. 11 and 12 well. The fits to the $\mathrm{C}^{18} \mathrm{O}(1-0)$ and (2-1) data are independent of each other. Therefore it is encouraging that the PMF output factors for both $\mathrm{C}^{18} \mathrm{O}$ transitions are similar in velocity and in spatial distribution. Because of the unambiguity of the fits for both transitions the factors, centred at -6.6 , -5.9 and $-5.4 \mathrm{~km} \mathrm{~s}^{-1}$, are referred to in the following as $1 n, 2 n$, and $3 n$, respectively.

The PMF factors, $1 n, 2 n$, and $3 n$, are distributed in a northsouth oriented ridge, in a pear-shaped body and a narrow
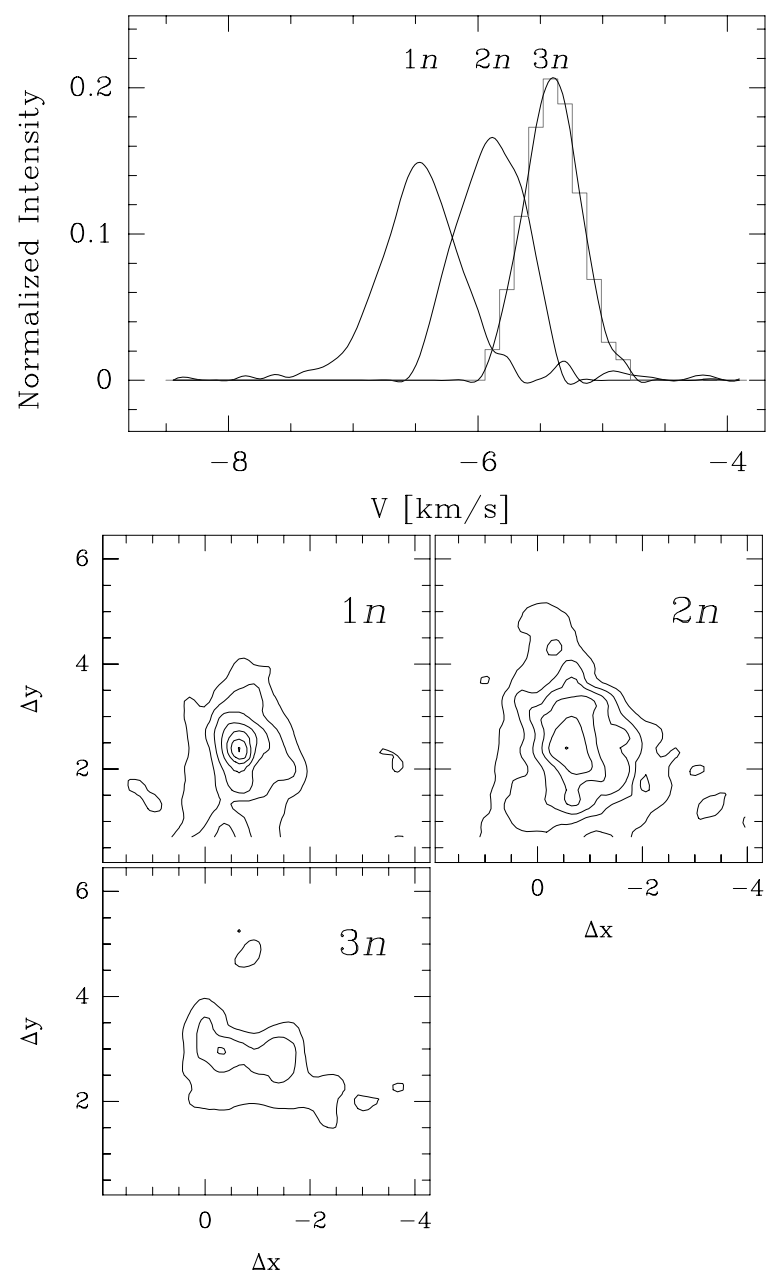

Fig. A.2. As Fig. A.1 but for $\mathrm{C}^{18} \mathrm{O}(2-1)$ data. Factor $3 n$ in the upper panel has been plotted also as a histogram to indicate velocity resolution of the input/output spectra.

east-west ridge, respectively. The $3 n$ factor lies at the velocity where the emission from the $\mathrm{H}^{13} \mathrm{CO}^{+}, \mathrm{DCO}^{+}$, and $\mathrm{N}_{2} \mathrm{H}^{+}$is at its maximum. Even though this factor is not readily evident in the individual spectra, PMF finds it in both $\mathrm{C}^{18} \mathrm{O}$ transitions. Factors $2 n$ and $3 n$ are symmetric, but factor $1 n$ has blue and redshifted wing-like emission, especially in the $(1-0)$ transition. According to the PMF fit the high $T_{\mathrm{A}}^{*}\left(\mathrm{C}^{18} \mathrm{O}(1-0)\right) / T_{\mathrm{A}}^{*}\left(\mathrm{C}^{18} \mathrm{O}(2-1)\right)$ ratio observed in the direction of $\mathrm{CG} 12-\mathrm{N}$ is due to the factor $2 n$.

If the number of factors in the PMF is chosen to be four, PMF divides in essence the factor $1 n$ into two, leaving the two other factors untouched. The spatial distribution of the split-up factors is similar to that of the $1 n$ in the three-factor PMF. If the number of factors is increased further to five, the result is similar to that with four factors, plus a fifth factor which has nearly zero intensity, "empty" field, in the map. The three factors are therefore sufficient to produce the velocity structure evident in Fig. 11, and increasing the number of factors does not improve the fit significantly.

\section{A.2. CG 12-S and CG 12-SW}

The results of the PMF fits, assuming four factors, to both observed $\mathrm{C}^{18} \mathrm{O}$ transitions in $\mathrm{CG} 12-\mathrm{S}$ are shown in Figs. A.3 and A.4. The location of the $\mathrm{DCO}^{+}$core is shown with a dashed 
L. K. Haikala and M. Olberg: The structure of the cometary globule CG 12, Online Material p 5
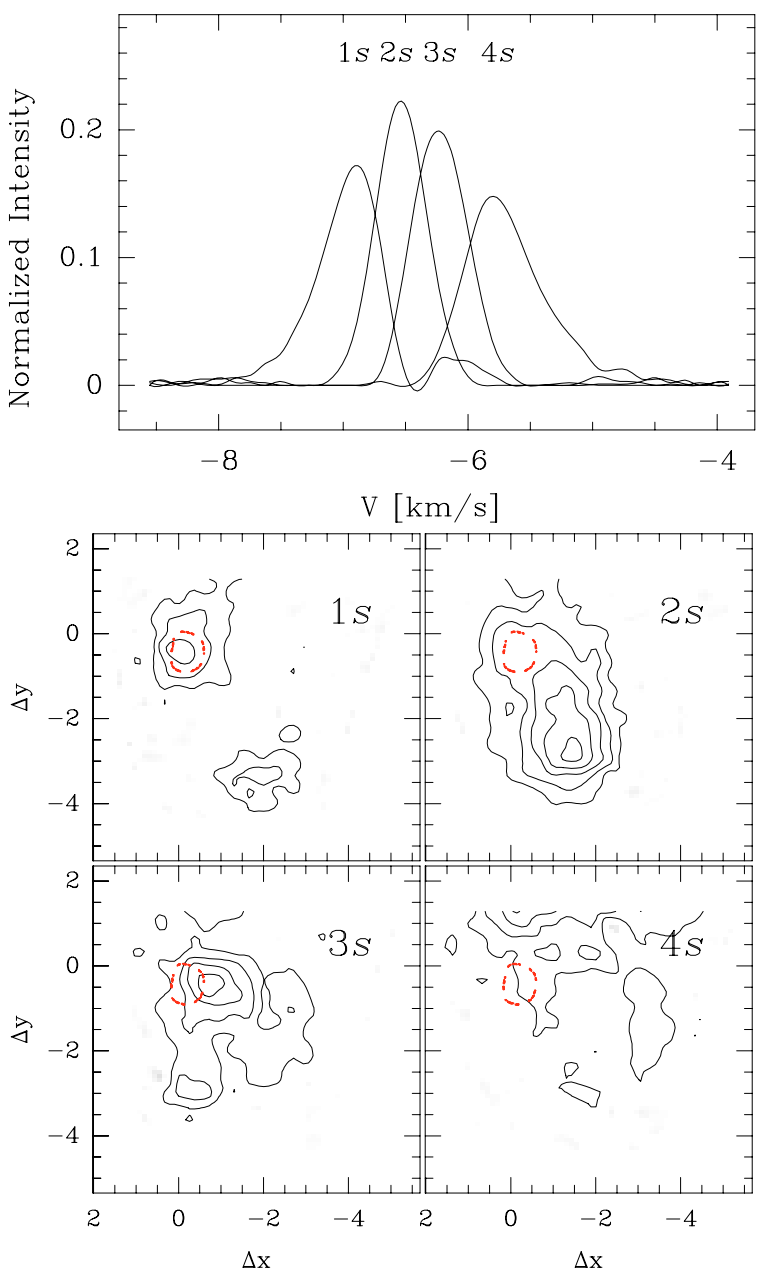

Fig. A.3. Upper panel: the basic spectral profiles calculated by the PMF in CG 12-S (four factor fit), $\mathrm{C}^{18} \mathrm{O}(1-0)$ data. Lower panels: the maps of the intensity of the basic factors. The factor numbers correspond to the numbers in the upper panel. The lowest contour level and increment is $0.2 \mathrm{~K} \mathrm{~km} \mathrm{~s}^{-1}$. The dashed contour outlines the $\mathrm{DCO}^{+}$core.

contour in the figures. The factors, centred at $-6.8,-6.4,-6.2$, and $-5.8 \mathrm{~km} \mathrm{~s}^{-1}$, will be referred to as $1 \mathrm{~s}$ to $4 \mathrm{~s}$, respectively.

The most redshifted factor $4 \mathrm{~s}$ covers the very northern part of the region, and is close in velocity to the $2 n$ factor in CG $12-\mathrm{N}$. It is natural to consider that this factor is due to emission extending from CG $12-\mathrm{N}$ to $\mathrm{CG} 12-\mathrm{S}$. Also the very faint emission observed in the northern part of the field in other three factors is at least partly due to emission from CG $12-\mathrm{N}$.

The emission from the most blueshifted factor $1 \mathrm{~s}$ is concentrated just below the $(0,0)$ position. The 2 s factor represents the arc which connects CG 12-S and CG 12-SW (Fig. 11). There is a small size, local maximum in the $\mathrm{C}^{18} \mathrm{O}(2-1) 2$ s factor north of the $\mathrm{DCO}^{+}$core. Even though this local maximum is not seen in the $\mathrm{C}^{18} \mathrm{O}(1-0) 2$ s factor, there is extended emission at its location. The southern part of the arc is more intense in the (1-0) transition than in the (2-1). The maximum of the southern extension coincides with CG $12-\mathrm{SW}$. The emission from the 3 s factor peaks west of the $\mathrm{DCO}^{+}$core, and is seen in both transitions.

\section{A.3. Individual line profiles}

The PMF fits to the $\mathrm{C}^{18} \mathrm{O}$ lines in the same selected positions as in Fig. 5, are shown in Fig. A.5. The residuals obtained by subtracting the added up PMF factors from the observed lines are
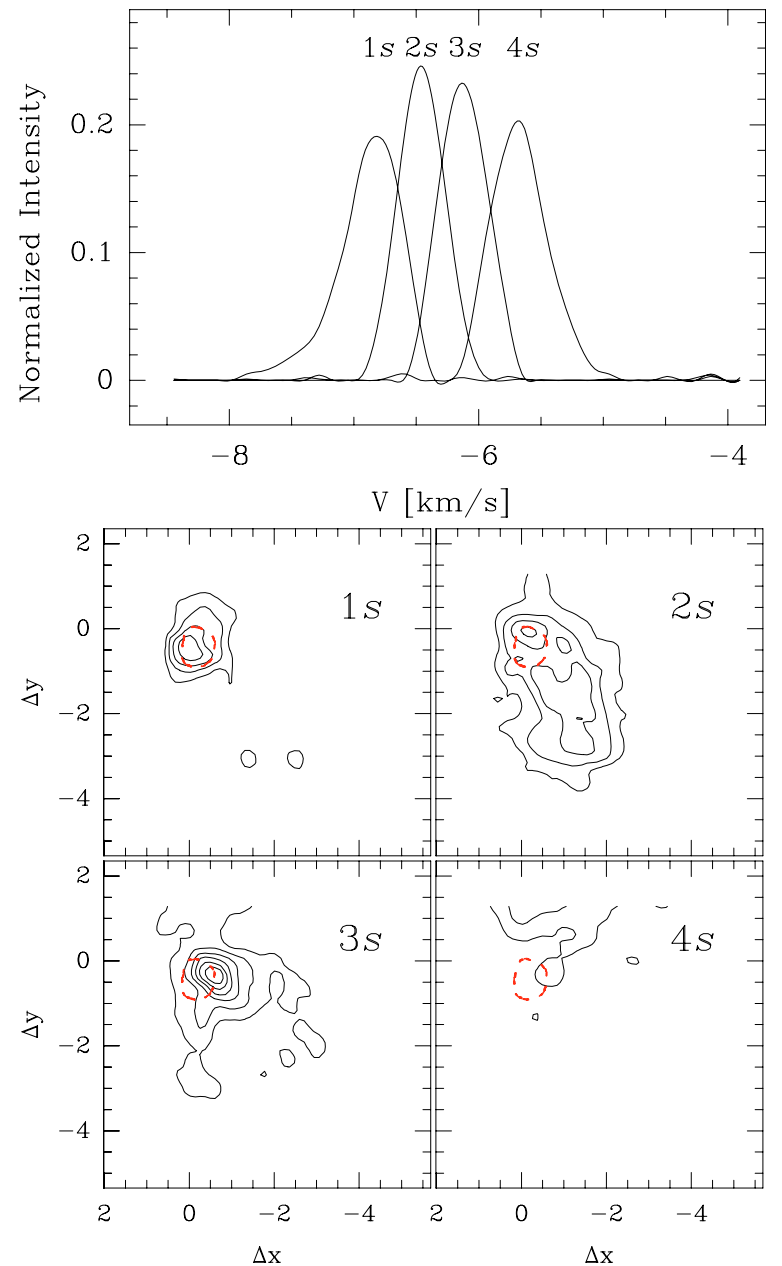

Fig. A.4. As Fig. A.3 but for $\mathrm{C}^{18} \mathrm{O}(2-1)$ data.

shown below the lines in the figure. A grey scale map of all the PMF fit residuals is shown in Fig. A.6. One should stress that, unlike a Gaussian multicomponent fit to a single spectrum, PMF fits, in this case 3 (CG 12-N) or 4 (CG 12-S) factors into all the input spectra simultaneously. Neither the shape nor the velocity of the factors is fixed in the fit. The two $\mathrm{C}^{18} \mathrm{O}$ transitions were fit separately, and PMF could have used factors differing in profile and velocity for the two transitions. The fitted PMF factors are, however, similar both in shape and velocity. The residuals shown in Figs. A.5 and A.6 are small, and demonstrate that PMF produces a good fit to the data.

The largest residual in Fig. A.5 takes place in the blue shifted side of the $\mathrm{C}^{18} \mathrm{O}(1-0)$ line in the centre of CG 12-N (position $\left.-40^{\prime \prime}, 160^{\prime \prime}\right)$. This would imply that the blue shifted wing of factor $\mathrm{C}^{18} \mathrm{O}(1-0) 1 n$ is too strong. A closer comparison of the input data and PMF results reveals that similar deviations take place for three other $\mathrm{C}^{18} \mathrm{O}(1-0)$ spectra around the position above. The $\mathrm{C}^{18} \mathrm{O}(1-0)$ line profiles farther away from the CG 12-N centre actually do have a more prominent blue shifted wing than the four above mentioned spectra. The large number of spectra with good fits outweighs the less optimal fit for the spectra in the centre of CG 12-N. The residuals shown in Fig. A.5 for the remaining four spectra in CG 12-S are smaller than in position $\left(-40^{\prime \prime}, 160^{\prime \prime}\right)$. 
L. K. Haikala and M. Olberg: The structure of the cometary globule CG 12, Online Material $p 6$

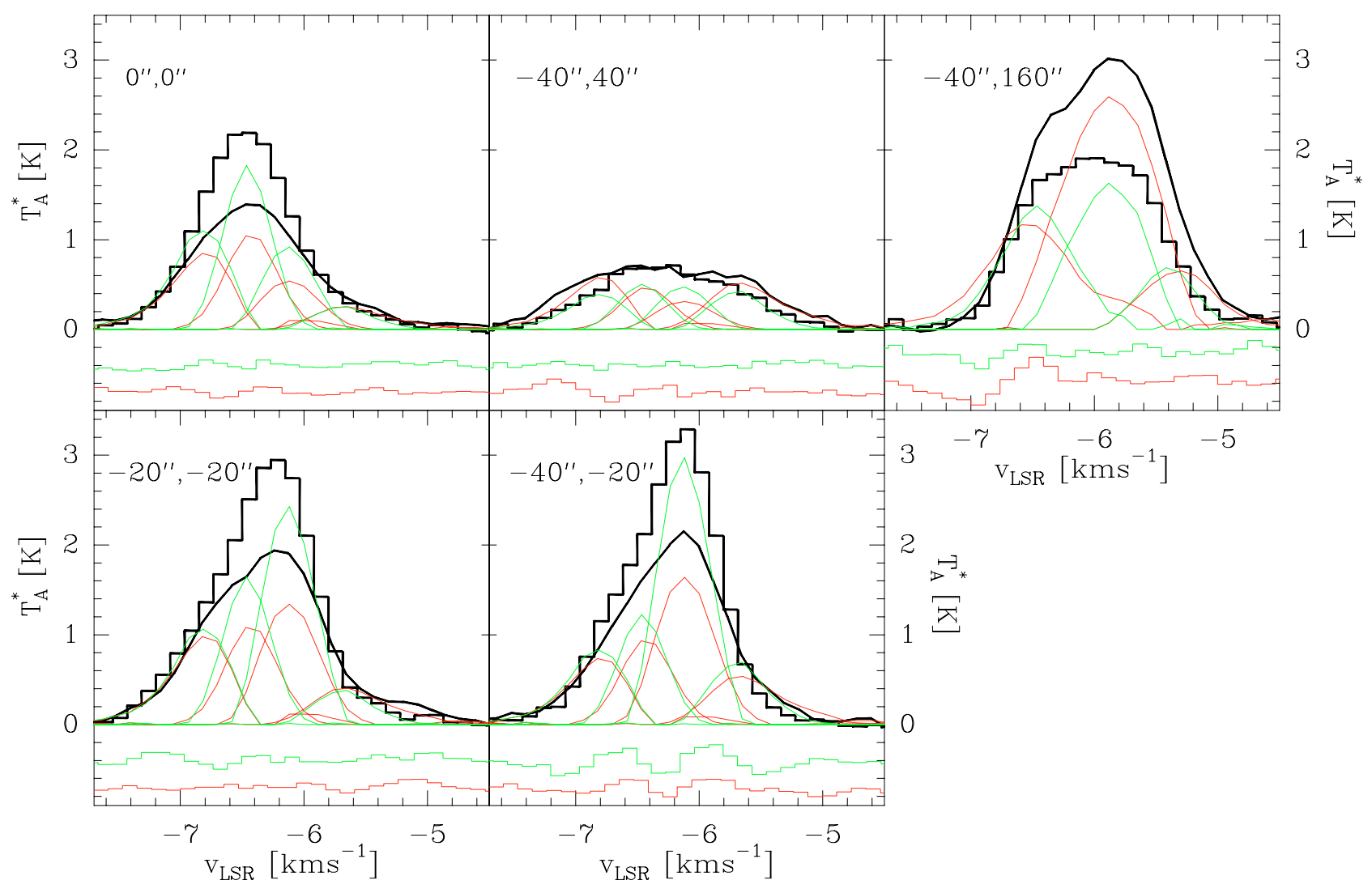

Fig. A.5. The PMF fit to the $\mathrm{C}^{18} \mathrm{O}$ lines in the selected positions positions in Fig. 5. The observed $\mathrm{C}^{18} \mathrm{O}(2-1)$ and (1-0) lines are plotted with a heavy histogram and line, respectively. The green and red lines show the fitted PMF $\mathrm{C}^{18} \mathrm{O}(2-1)$ and $(1-0)$ factors, respectively. The residuals of the fits are shown in the lower part of each panel.

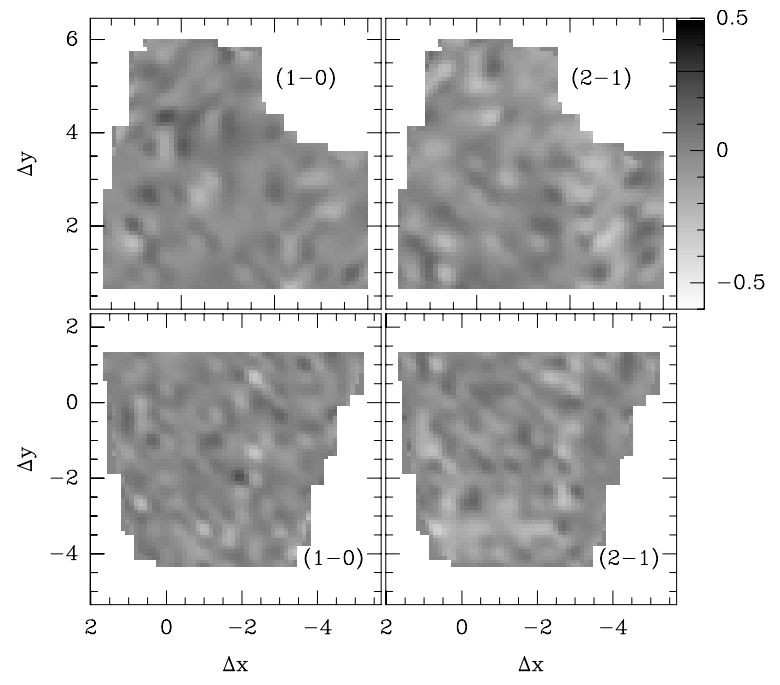

Fig. A.6. The PMF fit residuals in the $\mathrm{K} \mathrm{km} \mathrm{s}^{-1}$ scale. 